Article

\title{
Understanding the Relationship between Large-Scale Fold Structures and Small-Scale Fracture Patterns: A Case Study from the Oman Mountains
}

\author{
Mohammed H. N. Al-Kindi \\ Earth Sciences Consultancy Center, P.C. 611, Muscat P.O. Box 979, Oman; malkindi@gmail.com
}

Received: 5 August 2020; Accepted: 3 December 2020; Published: 4 December 2020

check for updates

\begin{abstract}
Considering the foreland fold belt of the Salakh Arch in the northern Oman Mountains, predictions made from two-dimensional (2D) restorations and geometrical analyses are tested here to assess the relationship between large-scale folds and small-scale fractures. The Salakh Arch is composed of six anticlines that are interpreted as faulted detachment folds. They have an overall stratigraphy of a 2-km-thick carbonate platform underlain by more than $1.5 \mathrm{~km}$ of interbedded sandstone and shale sequences. These sequences are most likely detached on a regionally extensive evaporite horizon. The folding of the Salakh Arch structures most likely occurred during the Neogene Period, and perhaps partly in the early Quaternary Period. This is evident from the thrusting of the Late Neogene Barzaman Formation which was deposited during the Late Neogene Period. Robust outcrop and subsurface fracture data are used to test these predictions. The results from the study indicate that most fractures are related to the orientation of the local structure, with some sets parallel and some sets perpendicular to local hinge lines. Prefolding regional fractures are also widely distributed, and these were mostly formed during the Late Cretaceous Period. Many pre-existing fractures are associated with faults that formed during the Late Cretaceous Period under a NW-SE compression. The local fractures generally have orientations that are consistent with being formed by the flexural slip/flexural flow of fold limbs and tangential longitudinal strains on fold hinges. These structures can be predicted from finite stratal dips, simple curvatures, and three-dimensional (3D) folding restoration maps. The Gaussian curvatures and 3D faulting restoration maps can be used as proxies for fault-related fractures. Local hinge-related fractures may reflect local tangential longitudinal strain during large-scale fold tightening. Fold structures that have formed at an oblique orientation to the regional shortening direction show additional fracture arrays perpendicular to the hinge, indicating weak axial extension. This is presumed to develop as the arcuate thrust belt of Salakh Arch was amplified. The analysis here illustrates the importance of taking a 3D approach, especially for noncylindrical folds. The protocols developed in this study and their results may have general applicability to investigations of fracture patterns in other folds.
\end{abstract}

Keywords: fold-related fractures; fault-related fractures; fracture prediction; Oman; petroleum reservoirs

\section{Introduction}

Bed-scale structural damage, in the form of fractures and small faults, can be important for hydrocarbon production [1-3]. These small structures are usually hard to map and predict in hydrocarbon reservoirs. This is mainly due to the limited resolution and coverage of data. Understanding fracture distributions along surface outcrops of folds can be very useful for mapping them in subsurface areas. This topic has been discussed for a long time, e.g., [4-8]. For example, Jamison [9] noted that the variations of the densities and apertures of fractures in the Canadian Monkshood detachment anticline do not correlate with a particular structural position. The fracture apertures display no 
consistent association with either fracture densities or lengths. Florez-Nino et al. [10] found a first-order relationship between the spacings and dimensions of fractures and the thickness of the confining stratigraphic sequence in the southern Bolivian Andes. Hanks et al. [11], working within the detachment folds of the Lisburne Group in the Brooks Range, considered lithology as the primary control for the fracture density. Hanks et al. [12] further added that the analysis of fold curvatures in the Lisburne Group is not a reliable method for predicting the density of fold-related fractures, and that fracture density data do not show a marked increase in fold hinges. The distribution of fractures within these folds suggests a strong relationship with flexural slip folding and penetrative strain [12]. In contrast, the authors of [13-15] presented a model in which fracture density was predicted based on the fold curvature, regardless of the type of folding. Murray [4] suggested that fracture density is constant along the fold geometry and that fracture aperture changes are proportional to the curvature. Mechanical approaches have also shown that the hinge curvature has a significant effect on fractures [3]. According to Hennings et al. [1], the rate of dip change for simple curvatures has a high correlation with the intensity of tectonically produced fractures. Li et al. [8] highlighted that the fracturing of faulted folds is controlled by the folding and faulting processes, and that the fracture areas in a fold can be divided into extensional, transitional, and shortening fracture areas.

Fractures within a folded surface might be a result of both regional and local fold-related stresses. Regional fractures are formed during the early stages of layer-parallel shortening. They are oriented orthogonally to beddings and usually trend perpendicularly and less-commonly parallel to the fold axis $[10,12,16]$. Local fold-related fractures exhibit a more complex relationship. According to Fischer and Wilkerson [16], joint orientations may vary according to the structural positions on the fold surface. Cosgrove and Ameen [2] demonstrated that fracture patterns vary with various types of folding. In buckle folds, which are also known as detachment folds in thin-skinned regimes, conjugate fractures form on the limbs and plunges because of hingeward-directed slips produced by flexural slip folding $[17,18]$. These fractures are frequent in thin bedded layers. However, tangential longitudinal strains are largest in thick layers characterized by flexure. These strains develop outer-arc dilatation fractures or normal faults and inner-arc minor thrusts. They are typically oriented parallel to the strikes in beds.

Some existing models that relate fracture distributions to their positions in major folds have been primarily based on field observations or general fold evolution assumptions. The results from these models are somewhat controversial. Thus, this study tests the fracture mapping that has been carried out for the folds of the Salakh Arch by considering some of the available models that predict fracture patterns from the geometrical features and evolution models of folds. The study makes use of the well-exposed and excellent carbonate outcrops of the Salakh Arch to map the fracture pattern and then compares the data with geometrical analysis and structural modeling at both the local and regional scales.

This article presents the outcrop fracture data gathered for the Salakh Arch folds. The folds differ significantly in terms of their geometries and structural positions. These differences allow evaluation of the effects of folding processes on fracture patterns. Geometrical and three-dimensional (3D) restoration attributes, as well as kinematic models, are utilized to explain the spatial distributions of fractures. Finally, the findings of this study are compared with previous models and assumptions that discuss the relationship between folds and fractures.

\section{Geological Setting}

\subsection{Study Area}

The Salakh Arch is a fold and thrust belt that is concave to the north and represents the southernmost part of the Oman Mountains. It is a chain of six doubly plunging anticlines with a collective length of $75 \mathrm{~km}$. These anticlines, from east to west, are the following: Jebel Madmar, Jebel Hinaydil, Salakh-E, Salakh-W, Jebel Nahdah, and Jebel Qusaibah (Figure 1). 


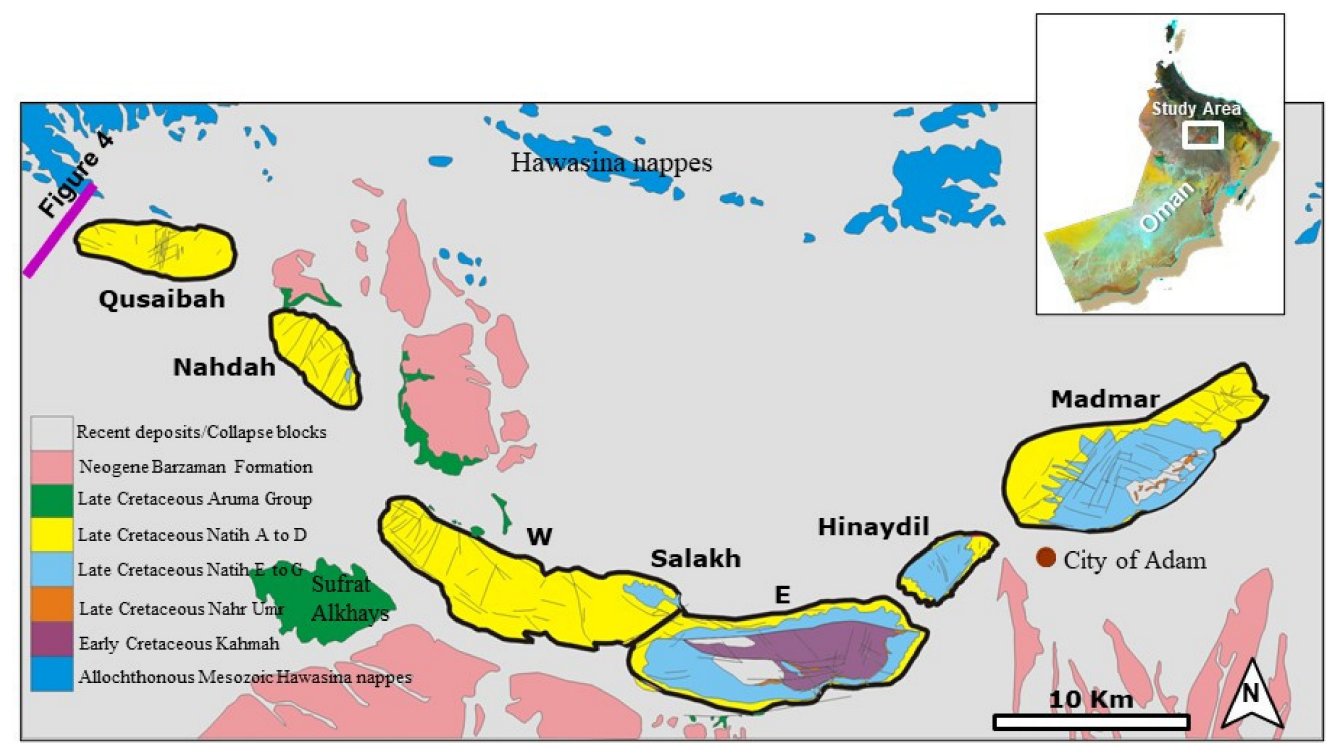

Figure 1. A geological map of the Salakh Arch. The inset shows the location of the Salakh Arch at a regional scale.

The Oman Mountains are the result of two major orogenies from the Late Cretaceous Period and later Cenozoic deformations. During the Late Cretaceous Period, the Tethyan Ocean, now only represented by the Sea of Oman, started to close coevally with the opening of the South Atlantic Ocean [19]. This closure led to the development of a NE-dipping subduction zone and an island arc complex [20]. The Arabian Plate progressed towards this subduction zone as the oceanic crust was consumed beneath it [21]. Significant volumes of the Mesozoic continental slope and deep-sea sediments (Hawasina units) with adjacent Tethyan oceanic plates (Semail Ophiolite) were obducted over the subduction zone and the eastern margin of the Arabian Platform [22,23]. As a consequence of the loading on the Arabian Platform, a foredeep basin (the Aruma foreland basin) rapidly developed south of the advancing thin-skinned thrust sheets of the allochthonous units [24]. The autochthonous units (ranging from the Precambrian to Late Cretaceous Periods) at the present-day Salakh Arch were deformed by minor extensional NW-SE faulting related to flexural downbending [25]. During the very end of the Santonian Age, greater India separated from Madagascar and raced northward to approach Eurasia. This movement created a component of the compression on the eastern margin of Oman [26]. The compression initiated a zone of sinistral transpression in the eastern margin [25]. According to Filbrandt et al. [27], the maximum horizontal compression direction south of the Oman Mountains was oriented NW-SE during the Late Santonian and Campanian and possibly into the early Cenozoic Era. They related this compression to the collision of the Indian-Afghan continent with the Arabian Plate during the Santonian to Campanian.

Several studies and models have interpreted the Oman Mountains as a result of Cenozoic compressional regimes. These regimes are related to the separation of the Arabian Plate from Africa along the Red Sea spreading zone and its subsequent northeastern movement and collision with the Eurasian Plate. The collision led to the formation of the Zagros foreland folding, e.g., [22,28]. Mount et al. [29] proposed that the main uplift of the Oman Mountains is related to compressional tectonics created in the early-to-middle Cenozoic Era. According to Loosveld et al. [25], the Oman Mountains were broadly uplifted during the Cenozoic Era with the completion of the mountain building process. In the transition from the Eocene Epoch to the Pliocene Epoch, as suggested in Loosveld et al. [25], the Salakh Arch was formed and the Fahud main fault was reactivated with a small sinistral component. During the same period, many normal faults were inverted to reverse faults, including the main Natih field fault. Searle et al. [30] and Boote et al. [28] also argued that the foreland deformation and uplift of the Oman Mountains was a consequence of the Arabian 
Platform collision with the Iranian crustal collage. This subsequently induced southward-directed transpression and inversion of the earlier rift margin. On the other hand, the thermal modeling done by Hansman et al. [31] indicates that the uplift of the central part of the Al Hajar Mountains was initiated 40 million years ago, during the Late Eocene Epoch, after the obduction process and before the Zagros collision. They proposed that the crustal thickening supporting the topography of the Al Hajar Mountains was caused by a slowdown of Makran subduction and that north Oman took up the residual fraction of N-S convergence between Arabia and Eurasia.

Both the structural evolution of the arch and its structural styles have been discussed in detail by Al-Kindi [32]. Overall, the Salakh Arch fold and thrust belt was formed by NNE-SSW compressional stresses during the Late Miocene/Early Pliocene Epoch, which possibly continued to the Early Pleistocene Epoch [32]. The folds in the arch are doubly plunging folds. As suggested by seismic data, some of them (e.g., those suggested by Jebel Qusaibah and Jebel Nahdah) are continuous in the subsurface, whereas others (e.g., those suggested Jebel Madmar and Jebel Hinaydil) are separated by strike-slip faults.

The burial is most likely not more than $3.5 \mathrm{~km}$, as suggested by the lack of significant ductile deformation and compaction features. A similar burial was found for the surrounding area by Aldega et al. [33] based on thermal sensitive clay mineral assemblages. Moraetis et al. [34] presented evidence of ongoing contractional tectonic activity in the Central Oman Mountains during the Quaternary, about 159 BP. This activity implies some reactivation of the Hawasina and Semail thrusts due to far-field stress either from the Makran Subduction Zone and/or the Zagros Collision Zone [34].

The timing of the final doming and deformation makes the outcrops of the Salakh Arch exceptionally good structural and stratigraphical analogues to the hydrocarbon-producing fields in the northern part of Oman (e.g., the Fahud and Natih fields). Both fields are among the largest fields in Oman in terms of oil-in-place, and they produce oil via the Natih reservoirs. The reservoirs are heavily fractured, and they are currently use oil/gas gravity drainage methods. These enhanced oil recovery methods are heavily dependent on a good understanding of fracture distributions and continuity.

\subsection{Stratigraphy of the Area}

Mapping was mainly performed in the Natih Formation, which was deposited during the Late Albian to Cenomanian [35]. The formation is divided into seven major units, ranging from Natih-A (youngest) to Natih-G (Figure 2). These units can be described as alternations between competent (Natih A, C, E, and G) and incompetent units (Natih B, D, and F). Natih-A and Natih-B consist of meter-scale and decimeter-scale beddings, respectively, of shallow marine limestone. Whereas Natih-A is composed of organic-poor cherty limestone, Natih-B is marked by organic-rich black argillaceous limestone. These two members are 115-m-thick. Natih-C and Natih-D are predominantly composed of thickly bedded, highly bioturbated clayey limestone. They are about $75 \mathrm{~m}$ in thickness. Natih-E is approximately 130 -m-thick. It is dominated by massive bioclastic limestone beds that can be several meters in thickness [36]. Natih-F and Natih-G are composed of marly limestone and a decimeter-scale bedding of whitish limestone, respectively. The total thickness of the Natih Formation in Salakh Arch is approximately $350-400 \mathrm{~m}$.

Figure 3 summarizes the subsurface stratigraphy of the main mechanical units in northern Oman. Package 1 represents the thick carbonate sequence that spans from the Permian to Late Cretaceous and package 2 represents the Paleozoic siliciclastic units. The thicknesses of the Paleozoic clastics significantly vary across the study area. The package disappears completely to the north at Jebel Akhdar, which is located about $80 \mathrm{~km}$ to the north of the Salakh Arch. Packages 1 and 2 are separated by the Permian unconformity. This unconformity marks the opening of the Neotethys Ocean. The packages are underlain by the Ara Salt. The salt forms a décollement layer that separates the Paleozoic clastics from the Proterozoic carbonates. The Ara Salt is also composed of a variety of lithologies, such as dolomite and limestone. It forms the weakest ductile package in the column. The basement in this work is considered to be all the units below the Ara Salt, including crystalline basement rocks. Package 1 is 
overlain by Cenozoic carbonate and clastic rocks that were primarily deposited during the Paleogene Period and Neogene Period, respectively. Further descriptions of these stratigraphic intervals have been discussed by Al-Kindi [32].

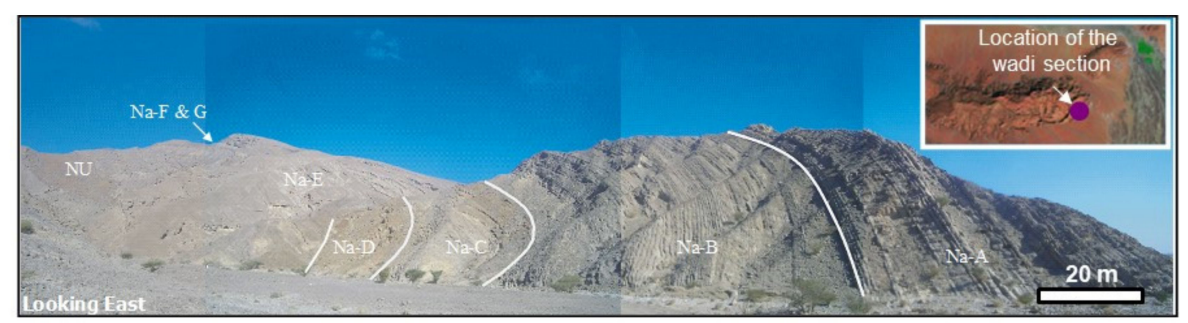

Figure 2. A valley section at Salakh-E, showing the seven members of the Natih Formation (Na-A to $\mathrm{Na}-\mathrm{G}$ ) and the Nahr Umr (NU) Formation. The coordinates of the location are $22^{\circ} 19^{\prime} 46^{\prime \prime} \mathrm{N}, 57^{\circ} 27^{\prime} 42^{\prime \prime} \mathrm{E}$.

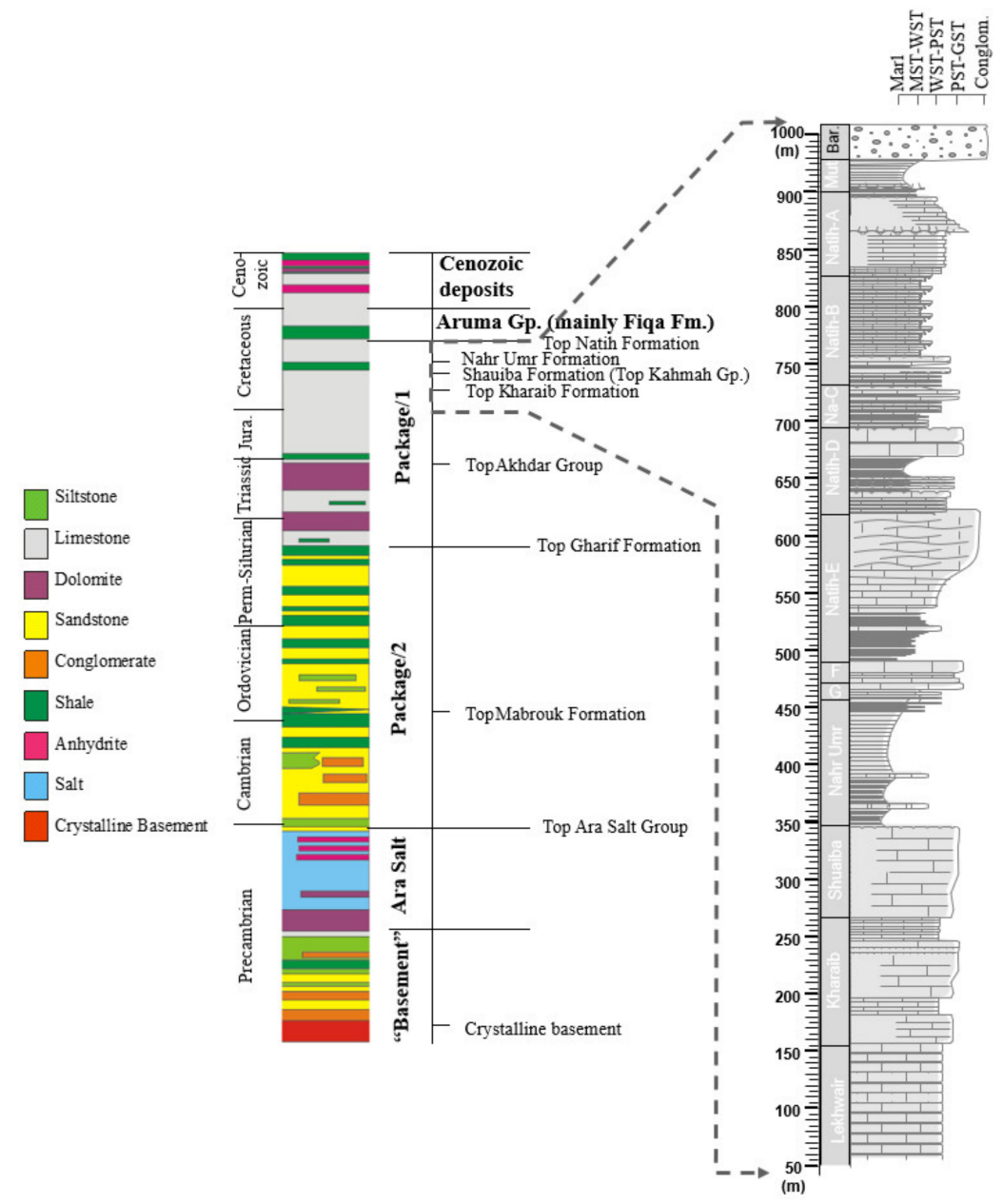

Figure 3. The left part of the figure shows a simplified stratigraphical column of the five main mechanical packages of Oman, including the Aruma and Cenozoic deposits, package 1, package 2, the Ara Salt, and the basement. The "basement" is considered to be all the units below the Ara Salt. The column also marks the positions of the interpreted horizons in the seismic sections. The thickness of package 1 is estimated to be $2 \mathrm{~km}$, whereas the thickness of package 2 varies between 1.5 and $3 \mathrm{~km}$. On the right, a stratigraphic column based on outcrops of the Barzaman Formation is shown. The conglomerates of the Barzaman Formation are Cenozoic deposits with interfingering formations of Dam limestone, also parts of the Muti, Natih, Nahr Umr, Shuaiba, Kharaib, and Lekhwair Formations [32]. The Cenozoic deposits and the Aruma Group are considered to be the cover sediments overlying package 1. 


\subsection{Structural Style of the Salakh Arch}

The central aim of this work is to assess the characteristics of large-scale structures that control the distributions of small-scale fractures, which can then be used for prediction. This requires a detailed structural model that describes the kinematic evolution of both the folds and the arcuate belt of the Salakh Arch. The structural evolution model used here was adapted from the one proposed by Al-Kindi [32]. The model proposes a faulted detachment fold model with a sole detachment along the Ara Salt (Figure 4). The positions of the folds of the Salakh Arch are most likely controlled by pre-existing faults that plausibly extend to the basement and cause an offset or step in the décollement unit of the Ara Salt. These faults have been reactive since at least the Early Paleozoic [26]. They have partly controlled the distribution of the Paleozoic sediments. Among other fault systems, the Maradi fault system, Fahud fault, and Natih fault have been active in different tectonic episodes, including NW-SE Late Cretaceous compression and the NE-SW Late Cenozoic compression [27,32,37,38]. The NW-SE Late Cretaceous compression was probably contemporaneous or post-dates the obduction of the Semail Ophiolite. The cause of this compression is still not well understood. Similar tectonic and evolution histories have been observed for the nearby structures of the Fahud, Natih, and Maradi zones [26]. Overall, the evolution of the structures of the Salakh Arch can be described as an interaction between pre-existing basement faults and shallow detachment faults. Unpublished gravity and magnetic data also show the presence of pre-existing basement faults in the area.
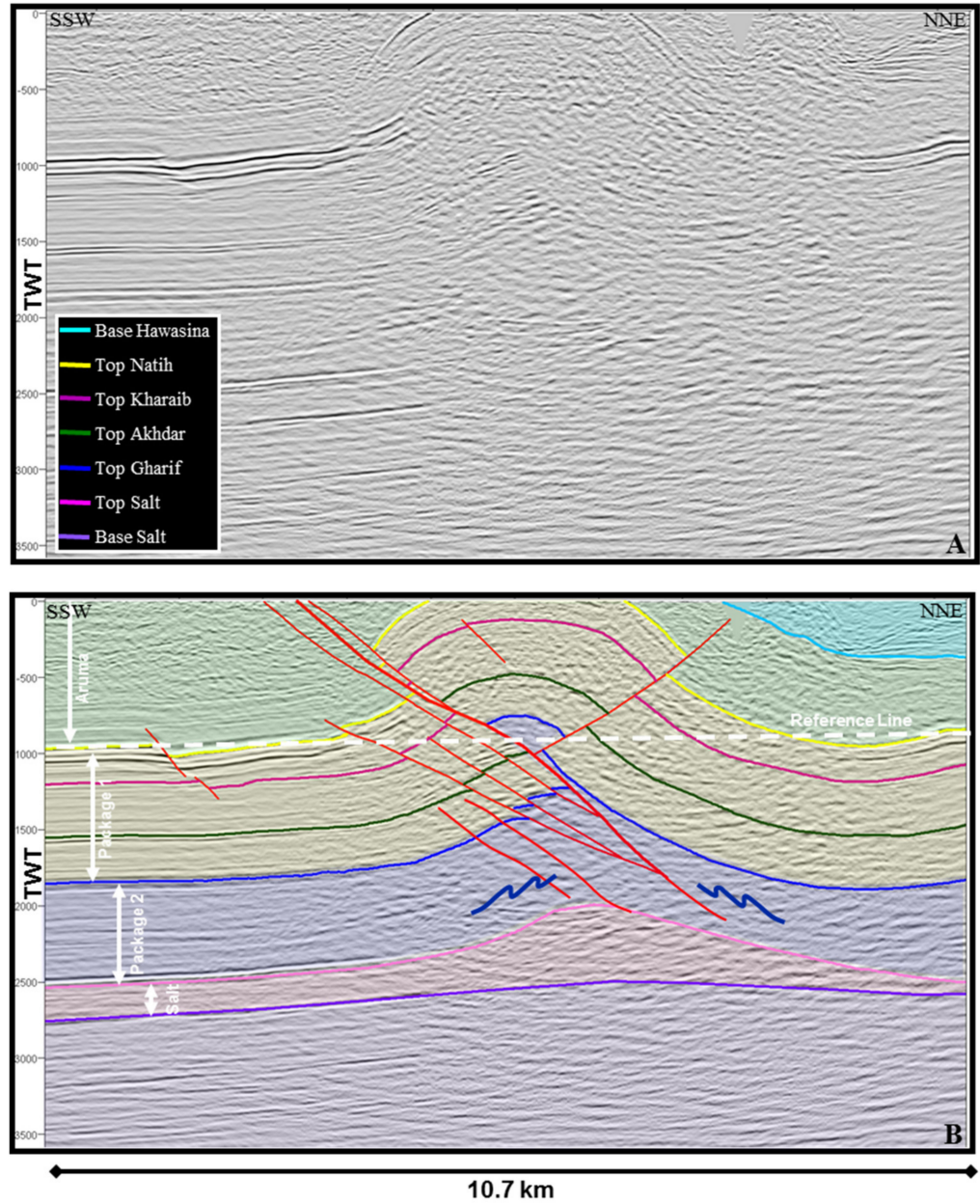

Figure 4. A seismic section through the Jebel Qusaibah structure. (A) Uninterpreted; (B) interpreted. The section is roughly perpendicular to the subsurface structure continuation of Jebel Qusaibah. The location of the section is shown in Figure 1. The structure is controlled by thrusting from both the front and back. 
According to Al-Kindi [32], the deformation of the outcropping Middle Miocene to Pliocene deposits and the displacement of the Cenozoic seismic reflectors implies that a process of folding and thrusting was active during the Neogene and possibly ceased during the Early Quaternary. Paleostress tensor analyses of the kinematic fault data, along with the fold axes trends, show that the regional stress regime has overall been directed to the south. Lateral movements over oblique or lateral ramps between the frontal ramps have caused local deflections of the regional stress trajectories. The two-dimensional (2D) restoration map shown by Al-Kindi [32], implies that the Salakh Arch was initiated as a primary arc and progressively advanced to the foreland. The restoration map of the arch predicts three areas of considerable clockwise or anticlockwise rotation that are related to differential shortening between adjacent segments.

According to Al-Kindi [32], most of the shortening in the Paleozoic stratigraphic unit of package 2 (Figure 3) is accommodated by folding. In contrast, the deformation along package 1 can be described as a transition between detachment folding and fault-propagation folding. Almost all the folds of the Salakh Arch have a box-fold geometry, with two limbs, two hinge zones, and a hinge area that is a flat to gently dipping area between the hinge zones (Figure 4). The folds of the Salakh Arch have been formed by a N-S to NNE-SSW regional compressional stress field during the Neogene to possibly early Quaternary. This is evident from the overthrusting of the Natih-E Formation on top of the Barzaman Formation. The Barzaman was deposited in the Miocene to Pliocene or plausibly Pleistocene, as observed in the southern side of Jebel Madmar. This compression is most likely related to the collision between Arabia and Eurasia. The collision is still on-going, causing a NE-SW compressional in-situ stress in Oman [33].

Figure 4 shows a seismic section through the Jebel Qusaibah structure. The seismic quality deteriorates within the fold core, making the interpretation and evaluation of the fold type uncertain. Part of the deformation in package 2 (weak interval) is possibly accommodated by internal strain (secondary folding and fracturing). The footwall synclines and associated syncline in the northern part of the structure suggest that the structure initially evolved as a buckle fold and that the bounding thrusts developed with further shortening. This is also supported by other seismic sections in the area. The structure has most likely detached within the salt (as supported by depth to detachment measurements) and the main frontal thrust may be detaching within package 2 or the salt.

\section{Methodology}

\subsection{Fracture Field Mapping}

The results presented in this study are heavily based on field data, the collection of which took about 6 months of field work. The main aim of the field mapping was to assess the relationship between the fracture distribution of the Salakh Arch with the following: (1) the evolution of the Salakh Arch fold and thrust as a whole system; (2) the development and growth of the individual folds in the arch. Only systematic fractures which were partially cemented or completely sealed by calcite were mapped to rule out any possible digenesis or stress release (exhumation) fractures. The exhumation fractures tend to be short, open, and irregularly spaced.

Fracture orientation data with about 600 vein measurements were collected in the field from various parts of the Jebel Madmar, Jebel Hinaydil, Jebel Salakh, and Jebel Nahdah structures to account for the overall fracture trends. These data were used to assess the relationship between the fracture distribution and evolution of the Salakh Arch system. In general, two fracture sampling areas were chosen per anticline, each with a size of roughly $400 \mathrm{~m}^{2}$, where one was in the crestal areas and another in the flanks. The results of the fracture mapping in Jebel Madmar, Jebel Hinaydil, Jebel Salakh, and Jebel Nahdah are discussed in Sections 4.2-4.6

Jebel Qusaibah (Figure 5) was selected to assess the relationship between the growth of folds and fracture distribution in detail. A comprehensive fracture mapping approach was used to map the fractures in Jebel Qusaibah. In general, Jebel Qusaibah was divided into 35 zones. In each area, 
a representative $400 \mathrm{~m}^{2}$ area (approximately $20 \mathrm{~m} \times 20 \mathrm{~m}$ ) was selected to map all the fractures within that area. In many cases, a few scanlines bisected the fracture sets in the considered area. The fracture data, including the orientation, filling, and type, were recorded along these scanlines. The 35 chosen areas were accessible and had well-exposed rock pavements of lower Natih-A beds, ensuring consistent mapping. About 4000 fracture measurements were taken from Jebel Qusaibah. The reason why Jebel Qusaibah was used to assess this relationship was because its terrains are well accessible, which allows the uniform mapping of fractures across all parts of the structure. The anticline also had fewer deformation complexities than others. Many seismic lines are also available around Jebel Qusaibah. These seismic lines allow one to capture the 3D geometry of Jebel Qusaibah in more detail than other folds and this helps to understand the evolution history of the structure.

The 35 areas at Jebel Qusaibah were selected to cover the whole anticline, apart from the middle zone, which was highly faulted (the white area in Figure 6). The fracture mapping was performed in the lower Natih-A beds, representing an outcropping throughout Jebel Qusaibah. This specific stratigraphic level was constantly used for the mapping at Jebel Qusaibah to relax the effect of bed thickness and lithology on the intensity of fracturing. The total thickness of the lower Natih-A beds is about $35 \mathrm{~m}$. These beds are characterized by a uniform bed thickness of about $0.5 \mathrm{~m}$ and uniform lithology of competent packstone and grainstone carbonates, as shown in Figure 3. All the fractures within the $400 \mathrm{~m}^{2}$ areas were mapped. These fractures were also classified as extensional or shear fractures. This classification was based on field mapping. Fractures that had slickensides on their walls were considered to be shear fractures. Moreover, shear fractures (modes II and III) may show either extensional or compressional associated features in their tips, for example, as horsetail fractures in one side, indicating extension, and stylolites in the other side, indicating compression or fractures with rotated sigmoidal tension gashes. Extensional fracture sets or open gashes (mode I) lack the presence of slickensides and unlike shear fractures can have associated plumose structures. They commonly have less structural complexity around their trajectories, although fringe zones can form at their tips. An example of a shear fracture with slickensides is shown in Figure 6C.

\subsection{Building 3D Model for Jebel Qusaibah}

A 3D model of Jebel Qusaibah with the top Natih area was created in Petrel by integrating multiple surface cross sections and geologically balanced seismic sections. The surface cross sections were constructed at a grid size of $500 \mathrm{~m}$, oriented both in parallel and perpendicular to Jebel Qusaibah. The model was restored in 3DMove to check for any volume excess or deficiency. The model was then used to analyze the geometrical features and evolution history of the Jebel Qusaibah structure.

\section{Results of Surface Fracture Mapping}

\subsection{Qusaibah}

Jebel Qusaibah is the westernmost pericline of the Salakh Arch. It is an open box fold with two rounded hinges and a gently dipping crest. The fold axis has an E-W trend. The Natih-A beds are exposed throughout the structure, whereas the members of Natih-B, Natih-C, and upper D are mostly exposed in the middle area (Figure 5). The fracture mapping in Jebel Qusaibah was conducted with the lower Natih-A beds. Several N-S normal faults have developed in the middle area of Jebel Qusaibah, perpendicular to the fold axis. The faults form a series of horst and graben structures. Two main sets of strike-slip faults developed at Jebel Qusaibah, trending NE-SW (dextral) and WNW-ESE (dextral and sinistral). The NE-striking set has mainly been formed in the eastern side, whereas the other set is dominant on the western side. 


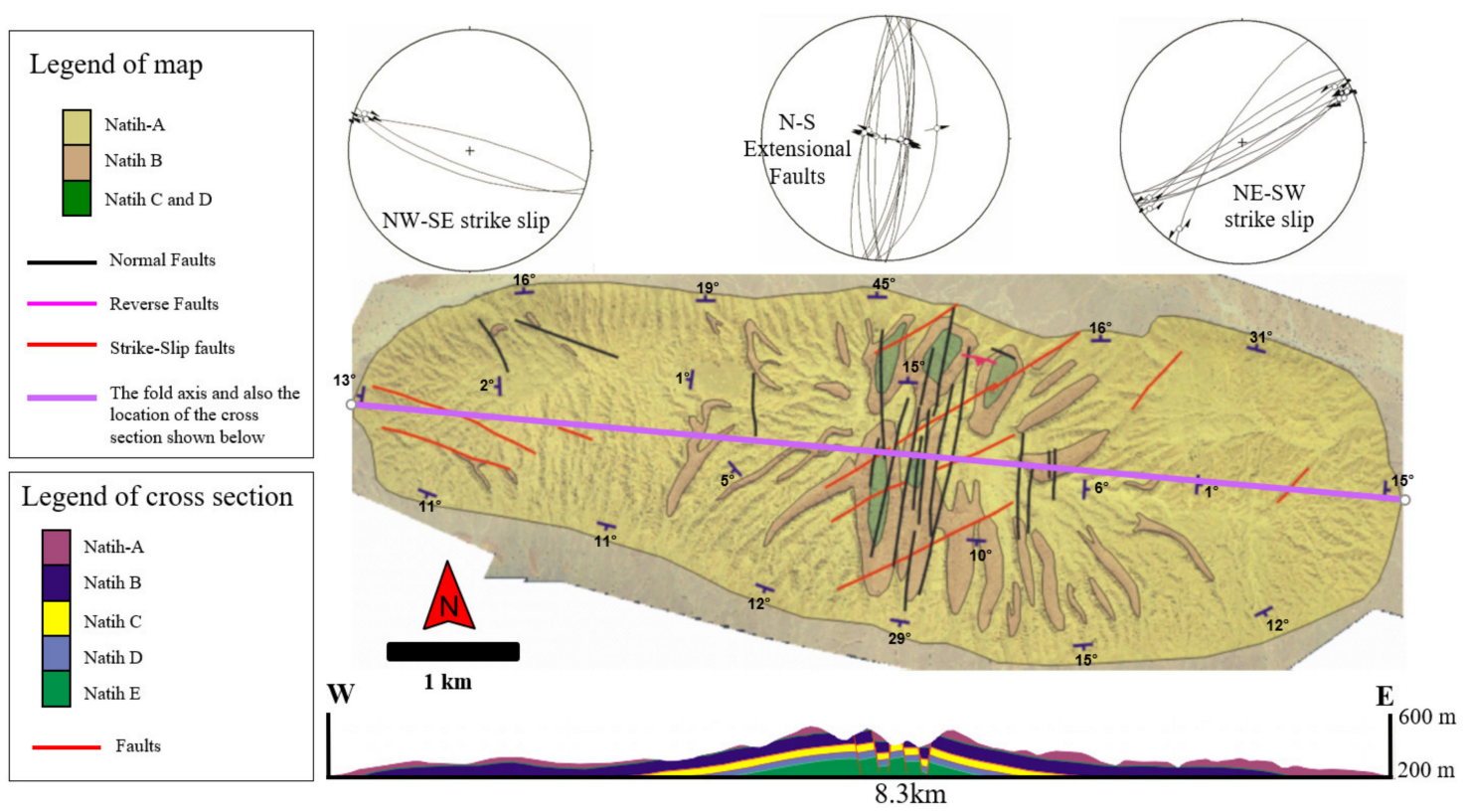

Figure 5. A geological map of Jebel Qusaibah with stereograms showing the trends and kinematics of the various mapped fault sets there. Series of horst and graben structures that formed in the middle dome of Jebel Qusaibah are shown by a cross section that runs parallel to the fold axis. The extensional faults decrease in throw toward the limbs.

A fracture density contour map was created to map the number of fractures in the 35 areas at Jebel Qusaibah (Figure 6). Zones 1 and 2 in the figure have relatively low fracture densities. The fracture density gradually increases towards the eastern part of the backlimb, where it reaches its maximum at area 6 with 229 fractures. The map does not include the middle area which is shown in white as it was highly faulted. The black and red areas denote normal and transtensional faults, respectively. In general, the mapped areas were selected far from the major fault planes to avoid zones with a high density of fault-related fractures. The color-coded key represents the number of fractures in various zones. Along with fracture density, Figure 6 also shows the distributions of shear (modes II and III) and extensional (mode I) fractures. The fracture orientations are illustrated using rose diagrams with sectors of equal area. The fracture densities are illustrated using contour lines. The fracture density was generally high in two parts, namely, the backlimb in the north and the western termination of the structure. The hinge and middle areas display two main sets that are oriented perpendicular (cross) and parallel (axial) to the fold axis. The fracture orientations in the two limbs and the plunges/ends of Jebel Qusaibah are generally different. The axial fracture set is not dominant in these areas. Two orthogonal sets (NE-SW and NW-SE) formed in the eastern end of Jebel Qusaibah. In contrast, the western side shows two fracture sets, NW-SE and E-W. The dominant set in the backlimb, in general, is trending E-W. There are few shear fractures in the hinge area and eastern plunge. According to Balsamo et al. [39], the NE-SW strike-slip faults at Jebel Qusaibah and some their associated fractures developed prior to the N-S extensional faults. The strike-slip faults formed at probably an early stage of folding, at depth of 3-4 km, whereas the extensional ones formed at later stages of folding at depths of less than $2 \mathrm{~km}$ [39]. 

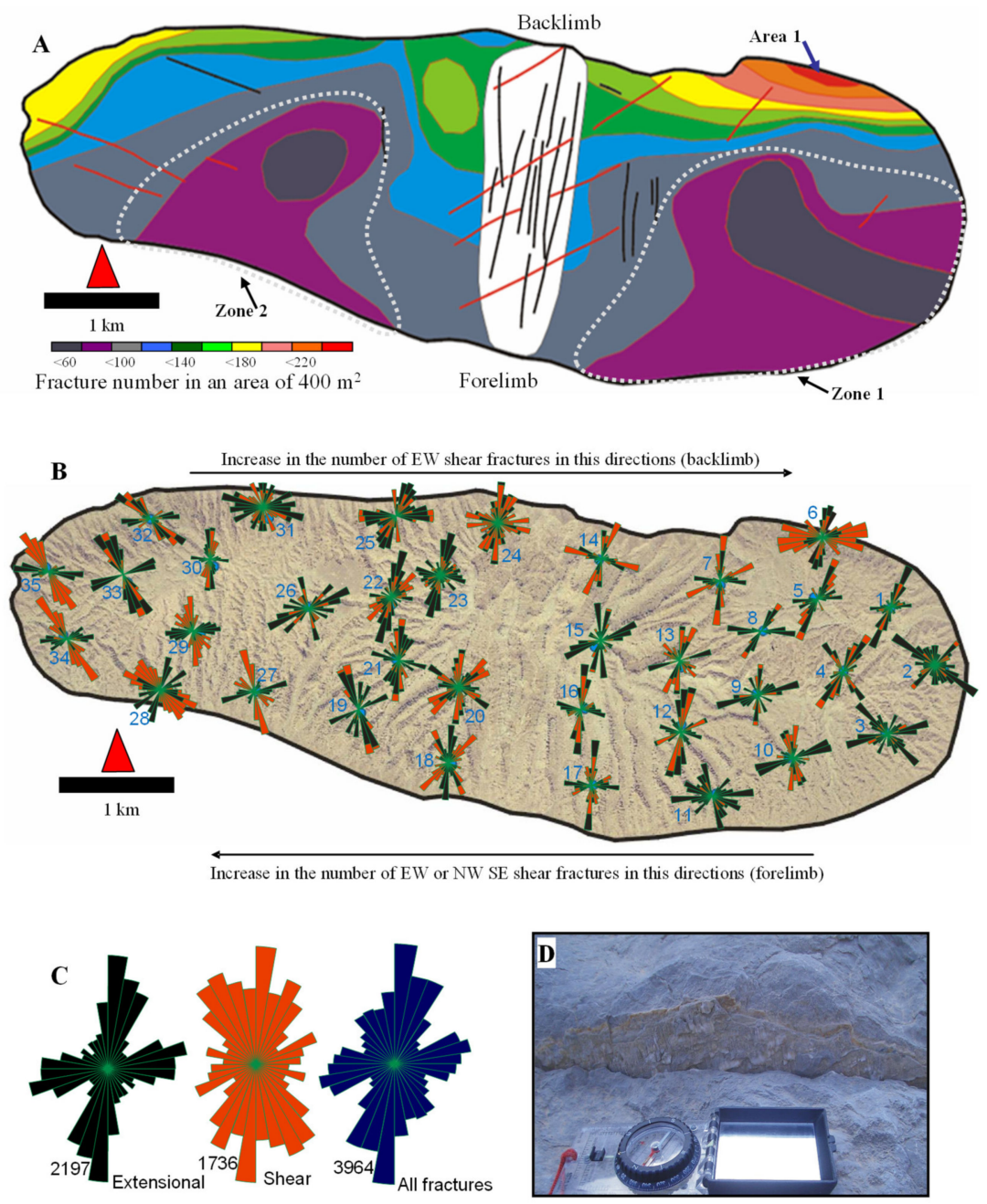

Figure 6. (A) Fracture density contour map created by linearly interpolating the fracture densities in the 35 areas at Jebel Qusaibah, along with the surface fault mapping. Red denotes strike-slip faults and black denotes normal faults. In general, the northern limb of Jebel Qusaibah (the backlimb) is more intensely fractured than the southern limb (the forelimb), particularly in the northeastern area (area 6), which is discussed further in the main text. (B) The distribution of extensional (black sectors in the rose diagrams) and shear fractures (red/orange sectors) as mapped in 35 areas at Jebel Qusaibah. The numbers of the areas are shown in blue. (C) Three rose diagrams showing the overall orientations of the shear, extensional, and all fractures at Jebel Qusaibah, respectively. The shear fractures oriented as open-mode extensional fractures are mostly dip-slip shear fractures, while those of the NNW-SSE and NNE-SSW faults are strike-slip fractures. (D) A typical E-W dip-slip shear fracture with slickensides that developed in area 6.

Table 1 shows the collected data for the 35 areas of Jebel Qusaibah with the bedding strike and dip, orientation of fractures, number of fractures, average apertures, length, dip, and filling. In general, there was no clear systematic relationship between the lengths or apertures of fractures and their densities. Here, aperture is the average perpendicular width of the fracture or vein. Most of the fracture sets were identified to be completely filled by calcite. The fractures were mainly found perpendicular to bedding. 
Table 1. Various measurements of fracture sets in the 35 areas of Jebel Qusaibah. Here, " $<>$ " is used as a symbol for averages, representing the average of all the measurements of fractures in the specified area. Partial fracture filling means that some fractures in the specified set were not completely filled/sealed by calcite.

\begin{tabular}{|c|c|c|c|c|c|c|c|}
\hline $\begin{array}{l}\text { Area } \\
\text { No. }\end{array}$ & $\begin{array}{c}\text { Bedding Plane, } \\
\text { Dip/Dip } \\
\text { Direction }\end{array}$ & $\begin{array}{c}<\text { Orientation }> \\
\text { of Sets }\end{array}$ & $\begin{array}{c}\text { No. } \\
\text { of Fractures }\end{array}$ & $\begin{array}{c}<\text { Aperture }> \\
\mathrm{mm}\end{array}$ & $\begin{array}{l}<\text { Length }>\text { m } \\
\text { of Some Sets }\end{array}$ & $\begin{array}{c}<\text { Dip }>/ \text { Dip } \\
\text { Direction of Some } \\
\text { Fracture Sets }\end{array}$ & $\begin{array}{c}\text { Complete/Partial } \\
\text { Filling }\end{array}$ \\
\hline 1 & $04 / 111$ & 205 & 80 & 6 & 10 & $84 / \mathrm{W}$ & Comp/part \\
\hline \multirow[b]{2}{*}{2} & \multirow[t]{2}{*}{$05 / 123$} & 235 & 36 & 4 & 6 & \multirow[b]{2}{*}{$76 / \mathrm{NE}$} & Comp \\
\hline & & 138 & 33 & 4 & 5 & & Comp \\
\hline \multirow[t]{2}{*}{3} & \multirow{2}{*}{$05 / 161$} & 257 & 4 & 5 & & & Comp/part \\
\hline & & 203 & 27 & 4 & & & Comp \\
\hline \multirow[b]{2}{*}{4} & \multirow[t]{2}{*}{ 07/092 } & 213 & 71 & 6 & 8 & & Comp \\
\hline & & 147 & 25 & 3 & 4 & & Comp \\
\hline 5 & $02 / 062$ & 258 & 73 & 6 & 22 & $77 / S$ & Comp \\
\hline \multirow{3}{*}{7} & \multirow[t]{3}{*}{$07 / 060$} & 182 & 82 & 5 & & $66 / \mathrm{W}$ & Comp/part \\
\hline & & 266 & 31 & 3 & & & Comp \\
\hline & & 244 & 29 & 3 & & & Comp \\
\hline & 01/054 & 216 & 28 & 5 & & $70 / \mathrm{W}$ & Comp/part \\
\hline 8 & & 274 & 19 & 3 & & 78/S & Comp \\
\hline & $02 / 128$ & 183 & 19 & 4 & & $75 / \mathrm{W}$ & Comp \\
\hline 9 & & 253 & 31 & 4 & 7 & $84 / \mathrm{N}$ & Comp \\
\hline & & 139 & 5 & 4 & & & Comp \\
\hline & $06 / 152$ & 170 & 55 & 5 & 9 & & Comp \\
\hline 10 & & 240 & 35 & 3 & 8 & $81 / \mathrm{W}$ & Comp \\
\hline & & 130 & 7 & 3 & & $77 / \mathrm{N}$ & Comp \\
\hline & 06/079 & 193 & 46 & 3 & 5 & $71 / \mathrm{W}$ & Comp \\
\hline 13 & & 252 & 16 & 3 & & & Comp \\
\hline & & 132 & 11 & 3 & 5 & & Comp \\
\hline & $26 / 015$ & 195 & 75 & 6 & 9 & $88 / \mathrm{W}$ & Comp \\
\hline 14 & & 287 & 60 & 5 & 11 & $57 / S$ & Comp \\
\hline & 03/086 & 189 & 49 & 4 & 5 & $82 / \mathrm{W}$ & Comp \\
\hline 15 & & 252 & 39 & 4 & 12 & $77 / \mathrm{N}$ & Comp \\
\hline & & 139 & 10 & 13 & & & Comp/part \\
\hline & 09/184 & 187 & 79 & 6 & 8 & $84 / \mathrm{E}$ & Comp \\
\hline 16 & & 271 & 26 & 6 & 7 & $75 / \mathrm{N}$ & Comp/part \\
\hline & $16 / 185$ & 182 & 60 & 5 & 8 & $80 / \mathrm{E}$ & Comp \\
\hline 17 & & 264 & 32 & 4 & 5 & $74 / \mathrm{N}$ & Comp \\
\hline & $19 / 201$ & 146 & 33 & 9 & 5 & $72 / \mathrm{E}$ & Comp/part \\
\hline 18 & & 194 & 30 & 13 & 8 & 69/E & Comp/part \\
\hline & & 229 & 29 & 6 & 7 & 79/NW & Comp \\
\hline & $10 / 219$ & 159 & 70 & 5 & 10 & $79 / \mathrm{NE}$ & Comp \\
\hline 19 & & 196 & 17 & 5 & & $75 / \mathrm{E}$ & Comp \\
\hline & & 244 & 11 & 4 & & $83 / \mathrm{N}$ & Comp \\
\hline & $13 / 235$ & 235 & 37 & 6 & 17 & 86/NW & Comp/part \\
\hline 20 & & 113 & 26 & 6 & 11 & & Comp/part \\
\hline
\end{tabular}


Table 1. Cont.

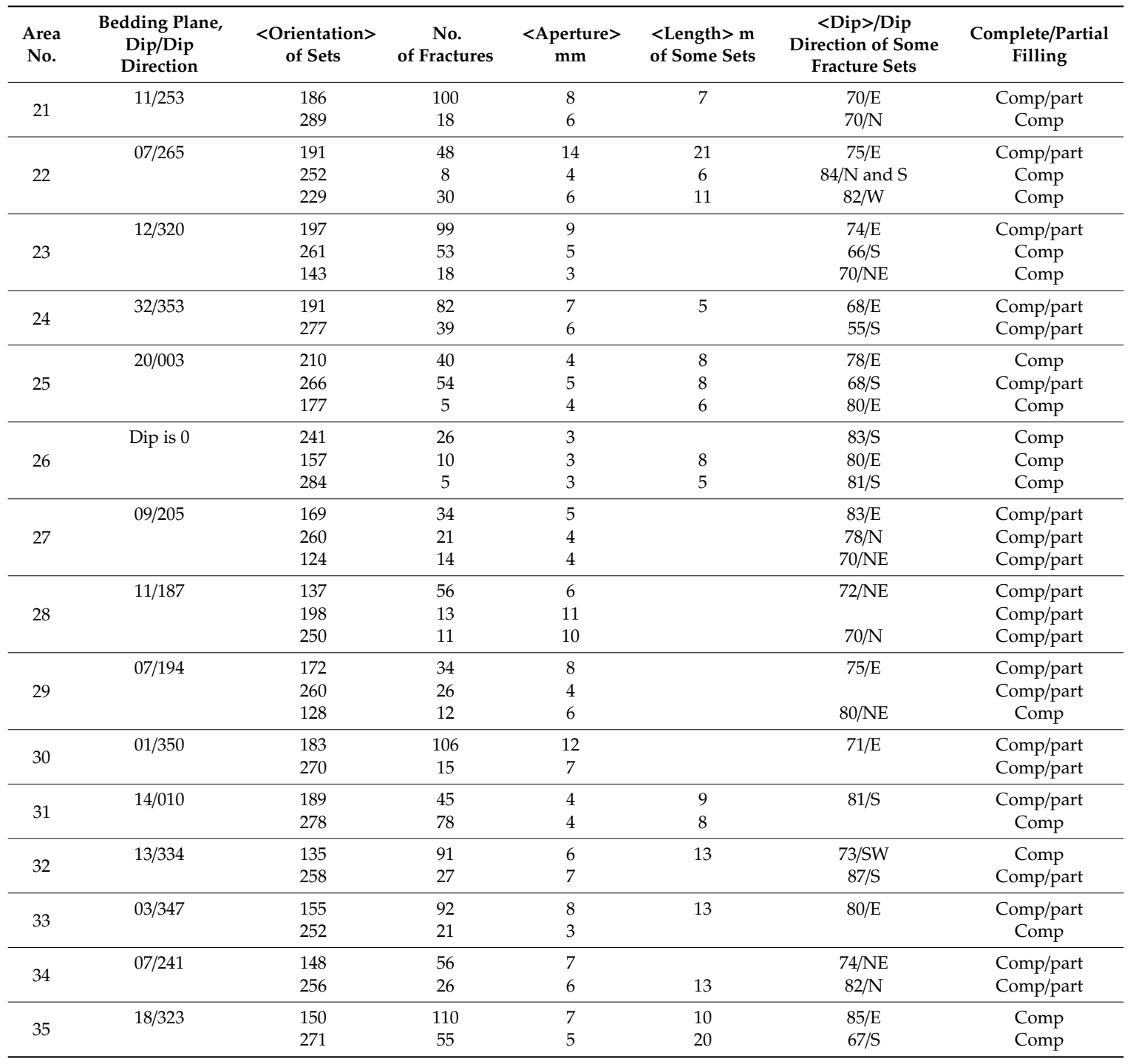

\subsection{Jebel Nahdah}

The following sections present general highlights from the fracture mapping in Jebel Madmar, Jebel Hinaydil, Jebel Salakh, and Jebel Nahdah. The collected field fracture data from these periclines are further presented and discussed in Section 5 .

Fold axis perpendicular tensile fractures developed in all parts of Jebel Nahdah, generally with apertures ranging between 1 and $4 \mathrm{~cm}$. Fold axis-parallel fractures are abundant in the hinge zones (high curvature). N-S fractures are also present throughout Jebel Nahdah and shear fractures are characteristically abundant in the southwestern corner.

\subsection{Salakh-W}

The western end of the fold is highly fractured by fold perpendicular extensional fractures with spacings of around $1 \mathrm{~m}$ and average apertures of more than $1 \mathrm{~cm}$. NW-SE shear fractures that are roughly parallel to the fold axis are also abundant in the two limbs of the western part of Salakh-W. These fractures are crosscut by the fold perpendicular extensional fractures. 


\subsection{Salakh-E}

The Salakh-E structure has a flat hinge area (typical box fold geometry) at the present elevation of more than $900 \mathrm{~m}$ above sea level, with highly curved hinge zones and steeply dipping to even overturned limbs. The fractures in the hinge area form two orthogonal sets that are perpendicular and parallel to the fold axis, with small apertures and 1.5-4 m spacings (Figure 7A). Small graben and horst structures, along with axial extensional fractures, are frequently found parallel to the fold axis in the tight hinge zones (Figure 8). These fractures decrease in frequency towards the flanks.

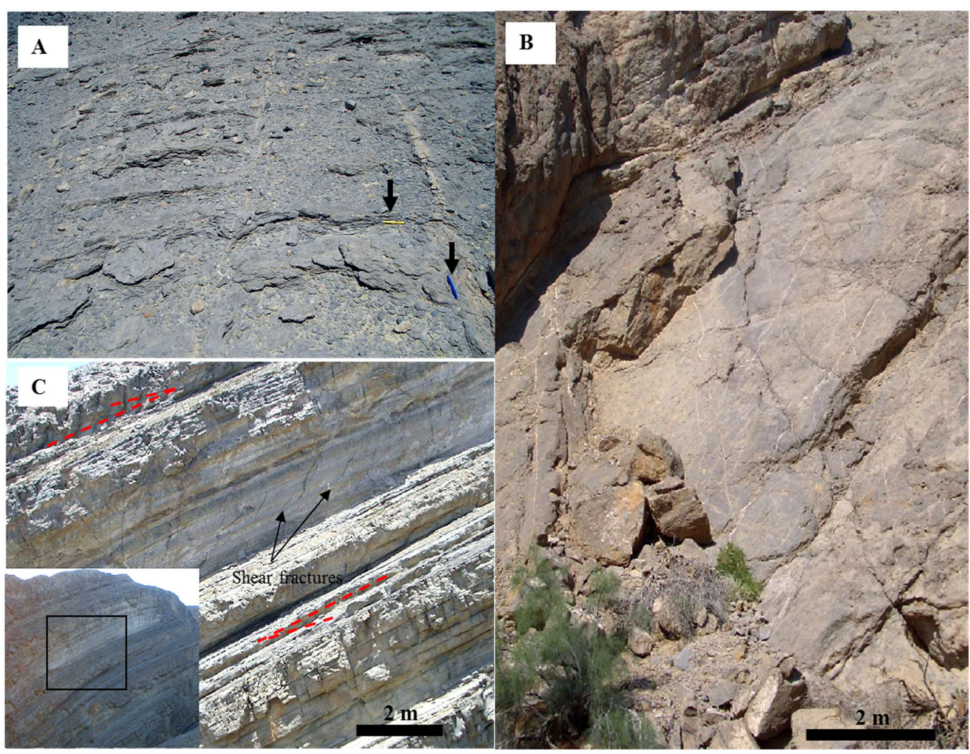

Figure 7. (A) The fracture pattern in the flat crest area of Salakh-E. These fractures are plausibly regional, as flat crests usually experience minor local strains related to the folding process. The view is eastward here. These fractures are usually long, planar, persistent, and perpendicular to bedding. They mainly trend NNE-SSW and ESE-WNW, i.e., perpendicular and parallel to the maximum compression axis. The black arrows indicate the scale. (B) Plausibly flexural slip-related fractures forming conjugate shear fractures in the forelimb of Salakh-E. These fractures typically form in beds that are bounded by layer-parallel detachments. The view is northward here. (C) Flexural flow-related shear fractures (black arrows) in the southern limb of Salakh-E. The view is westward here. The inset roughly shows the location of the fractures in the southern limb of Salakh-E. Note how the fracture pattern differs significantly along the overlying and underlying beds.
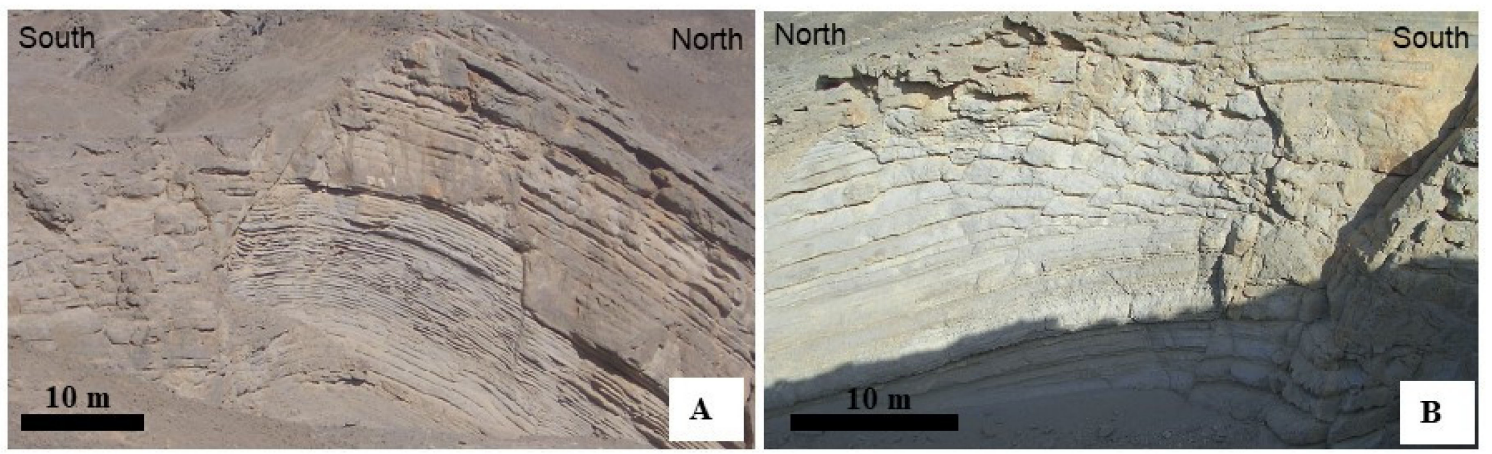

Figure 8. Examples of outer-arc extension-related structures in the hinges of Salakh-E. (A) Normal faults and (B) shear fractures. The structures are restricted in the hinge zones. Most of the fractures and the small faults disappear within the weaker units, whereas the larger faults are more persistent. The views are to the west and east, respectively. 
Conjugate shear fractures, often with an en échelon pattern, are found abundantly in the limbs of Salakh-E, particularly in the southern limbs (Figure 7B). These were perpendicular to the incline with respect to bedding and are usually formed in beds that are enclosed between layer-parallel slip surfaces. Several shear fractures that make an angle to the bedding also developed along the northern and southern limbs of Salakh-E (Figure 7C). Most of them are shear fractures with possible minor reverse displacement. They are oblique to the bedding and generally trend $\mathrm{E}-\mathrm{W}$, i.e., parallel to the fold axis. These fractures are clearly confined within single thick beds or sets of beds. These shear fracture sets disappear in the crestal areas.

\subsection{Jebel Hinaydil}

Fold axis perpendicular fractures were found throughout the whole structure of Jebel Hinaydil, and they were particularly abundant in the hinge zones (Figure 9). These fractures are normal to the bedding and develop mainly within the thick beds of Natih-E. In the eastern part of Jebel Hinaydil, the fractures are mainly shear fractures with a NE-SW orientation and horizontal slickensides along their planes. Intensive fracturing was also found parallel to the major fault in the southern part of the mountain.

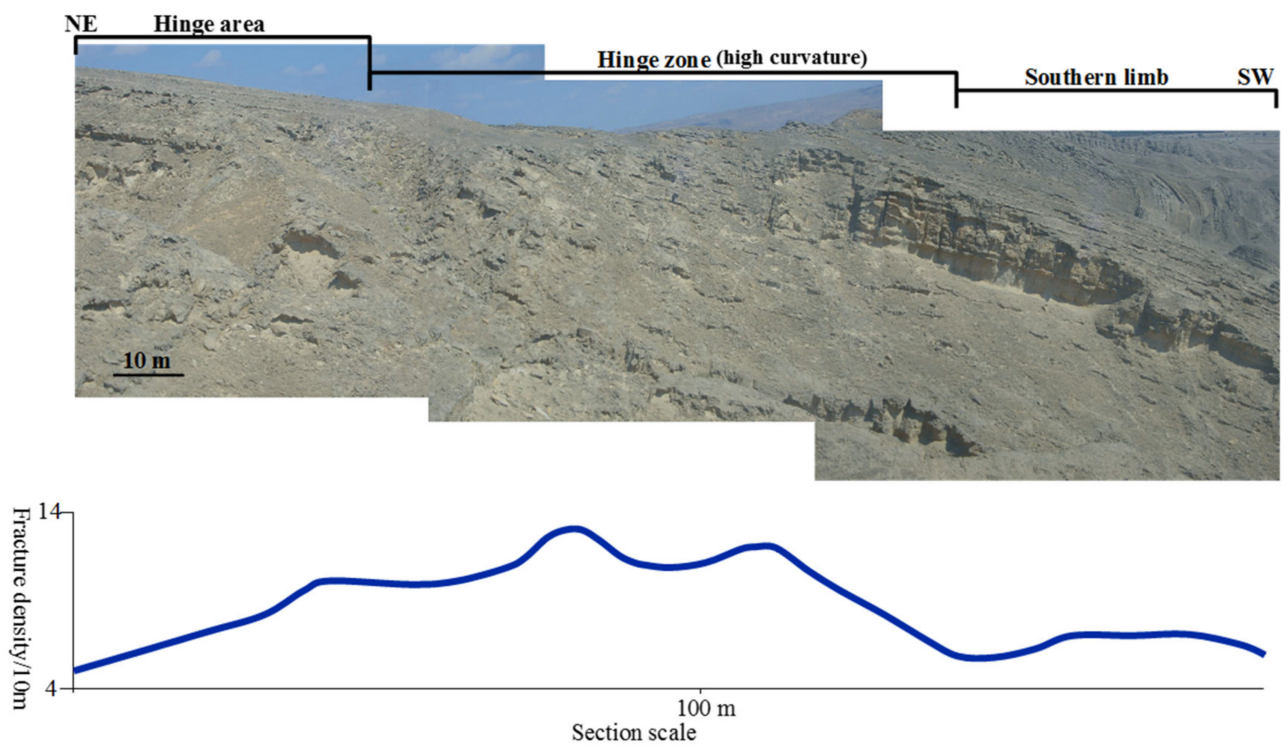

Figure 9. An outcrop section of the southern limb of Jebel Hinaydil, showing part of the limb, the hinge zone (the curved zone), and the hinge area (the flat to gently dipping crest of the fold). The maximum number of major fractures exists in the hinge zone and the density decreases towards the limb and the hinge areas. These fractures are most likely related to outer-arc extension.

\subsection{Madmar}

Jebel Madmar has a different fracture style than the other Salakh Arch folds. The fracture orientations and densities at Jebel Madmar are generally similar to the regional fault trends and densities. NE-SW fractures formed in all parts of Jebel Madmar. However, they were significantly enhanced in the curving part of the fold axis.

The NW-SE fractures are randomly distributed at Jebel Madmar, show different stages of filling, and are often porous in the middle. The majority of NW-SE fractures are cross-cut by the NE-SW set. Other fracture sets include N-S fractures, which developed mainly in the eastern end of Jebel Madmar, and $\mathrm{E}-\mathrm{W}$ fractures that were formed in the western plunge. Close to the main blind thrust at the southern side of Jebel Madmar, no significant extensional fractures are seen. Instead, out-of-sequence thrusts are frequent in the tight hinge areas (Figure 10). 


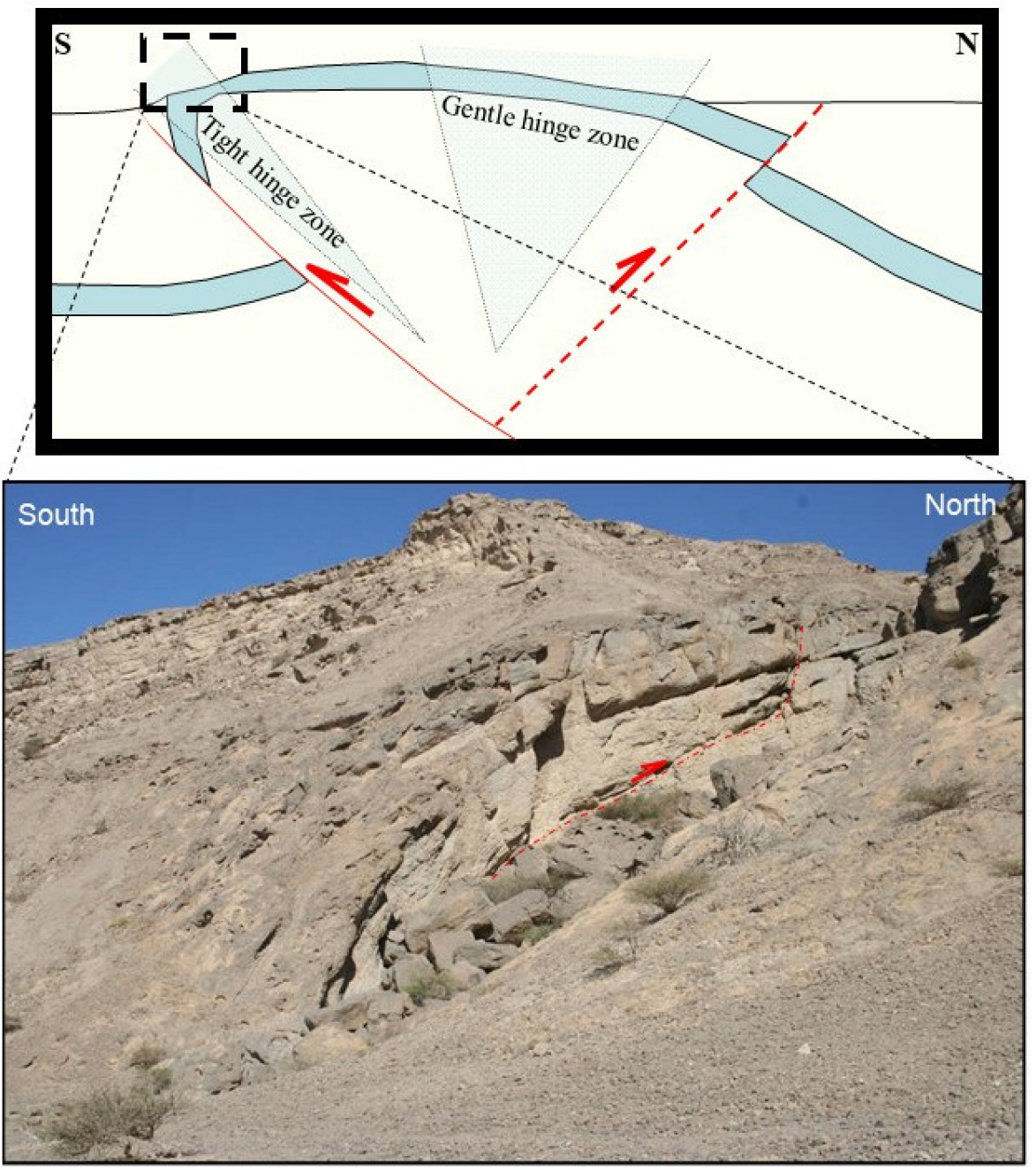

Figure 10. The photo shows a tight hinge zone in the southern limb of Jebel Madmar, close to the bounding southern thrust. The approximate location of this photo section in the structure of Jebel Madmar is shown as a box with dashed lines in the top figure. Out-of-sequent thrusts, e.g., the red dotted line in the photo, and shear fractures with minor reverse dip-slip movement formed in the tight hinge zone with almost no open-mode fractures, although the beds have high curvature. Although the limb here is highly curved, no open-mode fractures were noted.

\section{Overall Fracture Pattern at the Salakh Arch}

\subsection{Field Observations and Interpretation}

Several field observations and information from the published data of regional tectonics guided the classification of fractures during this study. This helped to determine the origins of fractures and to be able to understand their role in fluid migration, as well as predicting their patterns in subsurface areas. Prior discussions regarding the surface and subsurface areas surrounding the Salakh Arch, e.g., [26,27,40], helped to distinguish between prefolding fractures, synfolding fractures, and postfolding fractures. Distinguishment was also aided by considering the flat areas of the Salakh Arch and the cross-cutting relationships between fractures.

The prefolding fractures were generally of two types, i.e., NW-SE fractures that formed during the Late Cretaceous and can be seen across the whole of northern Oman and the general region [27], particularly northwestern Oman, and diagenesis-related fractures. Both the NW-SE and diagenesis-related fractures are bisected by other younger sets of fractures. The Late Cretaceous fractures form conjugate sets of NW-SE and WNW-ESE fractures [26]. No other prominent pre-existing fracture sets have 
been found at the Salakh Arch. The diagenesis and compaction-related fractures are usually filled by sediments from the same sedimentary strata [41]. These fractures are commonly irregular in shape and are generally small in length and height. Many diagenesis fractures were observed in the relatively incompetent units of argillaceous Natih-B and some bound the Natih channels in Natih-E and Natih-A. In contrast, systematic fracture sets feature regular orientations. They commonly have similar dimensions, types, dips, and spacings. The fracture mapping done in this work has only considered systematic fracture mapping.

The field data indicate that fractures related to the folding process differ significantly in terms of the densities between the various mechanical layers, where these layers respond differently to layer-parallel shear and longitudinal strains, for example, flexural slip and outer-arc extension (Figure 7B,C). In contrast, regional fractures, which are mostly formed in the early stages due to layer-parallel shortening, are usually persistent vertically and show regular spacings which are roughly consistent along various fold parts (Figure 7A). These regional sets have planar surfaces with broader lengths. Along arcuate fold and thrust belts, the orientations of regional fractures should be the same in frontal and oblique ramp zones unless these zones have undergone rotation or bending after the formation of the regional fractures. Notably, Jebel Qusaibah is located on a frontal zone of the arch.

The prominent historical maximum horizontal stress direction of the Cenozoic Era for the Salakh Arch and north Oman in general is NNE-SSW to NE-SW. This is also the in-situ stress direction in the arch and its surrounding area [27]. The NNE-SSW stress is the cause of the folding in the Salakh Arch, as highlighted by Al-Kindi [32]. The NE-SW fractures in the study area bisect the prefolding NW-SE fractures. As shown in Table 1, most of the NW-SE fracture sets are completely filled by calcite throughout Jebel Qusaibah, whereas the NE-SW fractures are both completely and partially filled. Similar observations have been noted in some petroleum fields in Oman [42]. Postfolding stress release or exhumation fractures are usually unfilled, as they are most likely formed after or in late stages of folding.

\subsection{Arch Scale}

The rose diagrams in Figure 11 show the overall orientations of fractures along the Salakh Arch. The orientations of fractures are different in various folds, suggesting strong relationships with local stresses. The fracture orientations seem to be strongly related to the local deformations formed during the evolution of Salakh Arch and its folds, as thoroughly explained by Al-Kindi [32]. The fractures are mainly parallel or perpendicular to fold axes. Conversely, the fractures at Jebel Madmar are slightly different because the main set does not show a strong relationship to the fold axis trend. Generally, both fracture orientation and density are highly influenced by fold axis orientation changes and any geometrical irregularities.

The Salakh Arch initiated as a primary arc (Al-Kindi, [32]). With progressive deformation, zones of either anticlockwise or clockwise rotations developed, resulting in arc-parallel extension in the Hinaydil structure and the western part of Salakh-W or oblique arc extension at Jebel Madmar, as illustrated in Figure 11. These zones are characterized by high densities of extensional and mode II shear fractures that trend as either parallel or oblique to the arc axis, respectively. This relationship demonstrates the effect of arc evolution kinematics in the formation of small-scale damage. The arc-parallel extension in the Jebel Nahdah zone is plausibly a result of the deflection of material as it moves along the oblique ramp, as demonstrated by cross-axial normal faults and intensive extensional fracturing. Unlike frontal ramps, oblique ramps encounter fold axis-parallel extension that is related to the arc shape evolution of fold and thrust belts. 


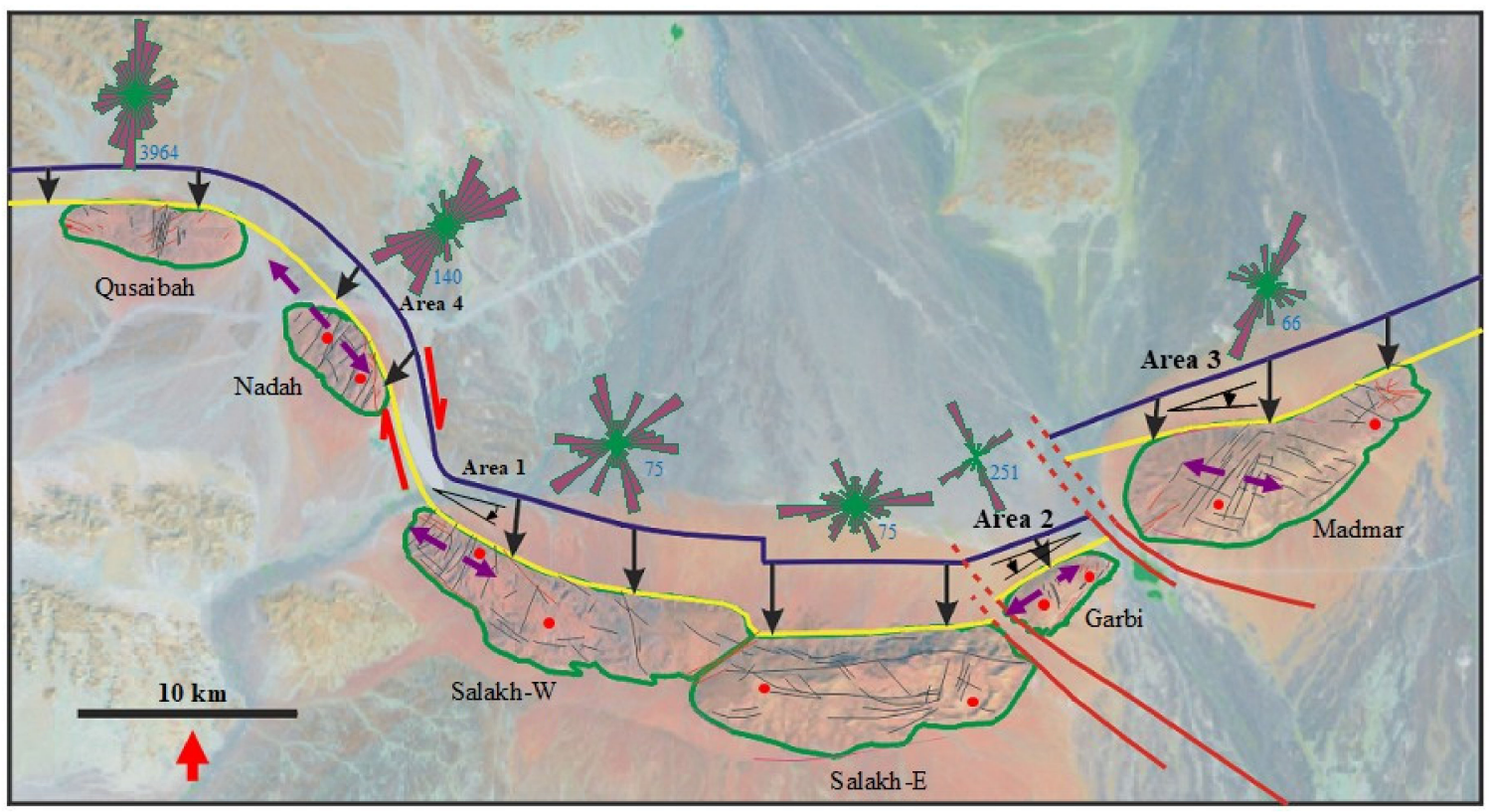

Figure 11. Comparison between the strains related to arc evolution and the small-scale structures seen in the outcrops of the Salakh Arch. The blue curve represents the initial position of the arc (as discussed by Al-Kindi [32]. This initial position was estimated from the calculated shortening values from a restored seismic section. The yellow curve is the present northern position of the arc. Areas 1, 2, and 3 present angular shear strains and thus longitudinal extension, as predicted by the arc map restoration. These areas correspond to extensional faults and fractures that developed perpendicularly to the predicted extension (purple arrows). High deflection of material in the oblique ramp of Jebel Nahdah caused arc-parallel extension. In general, the fracture data across the arch are shown as rose diagrams, with the number of fractures shown in blue next to the diagrams and the approximate locations of where the fractures were collected shown as red dots. These data were collected through scanlines in the indicated locations. The fracture orientations change across the Salakh Arch, indicating strong relationships to local arch evolution and folding mechanisms.

\subsection{Fold Scale}

The geometries of some folds are highly controlled by bounding thrusts. For example, Jebel Madmar is strongly asymmetric with a gently dipping southern limb and inverted northern limb. These folds mainly exhibit regional fractures, arc evolution-related fractures, and fault-related fractures. Fold-related fractures are less common in open folds. On the contrary, other anticlines (e.g., Salakh-E) show significant limb rotation and tight hinges, indicating greater folding-accommodated shortening. These folds exhibit various types of fold-related fractures that can be related to local strains produced by three folding mechanisms, namely, flexural slippage, flexural flow, and tangential longitudinal strain. Tangential longitudinal strain is mainly present in the highly curved parts and produces fold axis parallel faults and fractures as seen in Jebel Hinaydil and Jebel Salakh-E in Figures 10 and 11, respectively. This strain is increasingly operative during the late stages of folding and mainly affects competent thick units or homogenous thinner beds that behave as a single massive unit. The resulting fractures are perpendicular or slightly oblique to the bedding.

Flexural slippage and flexural flow folding are localized in the limb areas. These areas are characterized by layer-parallel slip surfaces, as in the case of the limbs of Salakh-E in Figure 7A and Jebel Nahdah. Flexural slip folding introduces local maximum compressional stress ( $\sigma \mathrm{Hmax}$ ) because of thrusting in the slip surfaces and results in fractures [14]. These fractures are mostly conjugate sets with the bisector always pointing toward the fold hinge. The shear fractures that make an angle to the bedding in the limbs of Salakh-E (Figure 7C) are plausibly associated with simple shear strain, especially where the layer interfaces show layer-parallel slickensides. This simple shear strain was 
probably formed by flexural folding, whereby the shearing is completely or partially accommodated by the internal simple shear within the host beds. In general, the simple shear strain in flexural slip folding is exclusively accommodated by the slips on bounding detachments, while the strain of flexural flow is taken up via the internal flow of the deformed units $[43,44]$. Flexural flow can be represented by shear fractures or sigmoidal tension gashes, and flexural slips produce layer-parallel fractures and can be identified by their intensive layer-parallel detachments.

\subsection{D Modeling and Outcrop Fracture Pattern at Jebel Qusaibah}

The collected fracture data of Jebel Qusaibah and the 3D model of the whole structure provides a good opportunity to relate small structures in various parts of folds to various geometrical attributes of the model, as well as to the amounts of strain produced by the folding process and the movements from bounding thrusts. Several attributes (Figure 12) were utilized to analyze the top Natih Formation of the Jebel Qusaibah structure using the 3DMove software package. These attributes are detailed in the sections below.
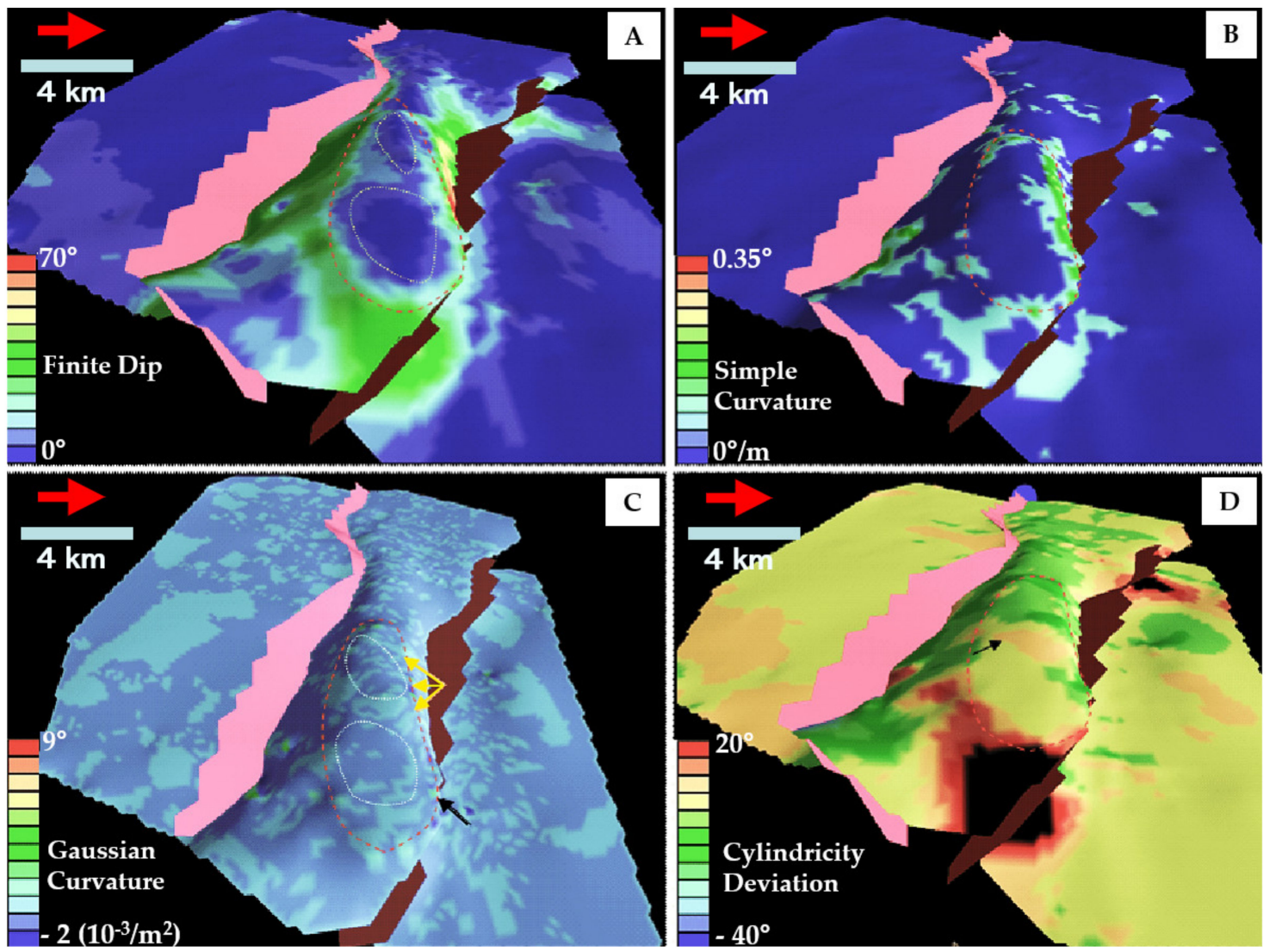

Figure 12. Analysis of the three-dimensional (3D) map of Jebel Qusaibah. The red dotted areas in all figures roughly show the surface position of Jebel Qusaibah and the red arrows indicate north. The pink surfaces are the fore and back thrusts. The surfaces of both thrusts are continuous above the top Natih surfaces. (A) Finite dip map, where the blue areas at the position of Jebel Qusaibah represent zero dip magnitudes that also correspond to the areas with a low fracture density as in Figure 5. (B) Simple curvature map. (C) Gaussian curvature map, where approximately zero Gaussian curvature occurs in two regions, denoted by the white dotted areas. High values are observed in the northeastern corner (black arrow) and the western parts of the backlimb (orange arrows). (D) Cylindricity deviation map is found useful to map irregular deformation at the eastern side of Jebel Qusaibah, where the fold structure bends from a frontal ramp (Jebel Qusaibah) to an oblique ramp (Jebel Nahdah). 


\subsection{Static Geometrical Analysis}

The finite dip map at the position of Jebel Qusaibah shows two zones with dip magnitudes of approximately zero. These zones correspond to the zones with low surface fracture densities marked in Figure 6A. Generally, the finite dip map can be a good proxy for limb rotation. Thus, it can be used to predict flexural folding-related fractures.

Simple curvature measures the rate of dip change. The maximum dip changes at Jebel Qusaibah were found at the backlimb and the northern hinge zones, with values of no less than $0.25^{\circ}$ per $\mathrm{m}$. The 100-fracture density contour line (see Figure 6A) follows the zone with a high rate of dip change. The simple curvature map also reveals high values of dip change in the western end of Jebel Qusaibah, roughly corresponding to the zones that have a high number of fractures. The simple curvature map is, in general, a good representative of the amount of tangential longitudinal strains and the related fractures.

A Gaussian curvature or total curvature is, in simple terms, the product of the two maximum curvatures for a particular plane. A Gaussian curvature can be a useful measure for abnormal strains [13-15,44], and subsequently fracture density predictions within a folded surface because it can calculate the degree to which a layer has been stretched or compressed to form noncylindrical folds such as periclines or saddles [13]. Analysis by Gaussian curvatures can also help with identifying small domains within a large fold surface that have minor periclinal geometries and are more likely to fracture than adjacent areas. The Gaussian curvature map of Jebel Qusaibah shows high values at the northeastern corner, which roughly corresponds to area 6 in Figure 6A. According to the outcrop observations, a minor pericline developed in this corner. Such small periclines could be unpredictable in the subsurface and further analyses, such as Gaussian curvature analyses, are required to identify them. Jebel Qusaibah also has high Gaussian curvature values at the western areas that feature a relatively high fracture density.

\subsection{D Restoration}

The 3D model of the Jebel Qusaibah fold was restored using 3DMove. The restoration process provides a four-dimensional (including relative timing) understanding of the structure. It measures the magnitudes of strain formed by the faulting and the folding kinematics in various parts of the restored structure. The restoration was performed along an axis trending N-S, i.e., parallel to the regional shortening axis.

The restoration of the displacements along the backthrust and the forethrust was performed using a fault parallel flow algorithm, which restores the hanging wall movements by layer-parallel slip on bedding surface with zero fault slip at the fault tip line (Wilkerson et al., 1991). The accumulative strains that resulted from the movements along the bounding thrusts are shown in Figure 13A. They range from 0 to about -0.12 (minus sign indicates contraction). High strain occurs at the northeastern corner which corresponds to the area of maximum fracture density (i.e., area 6). This local strain was produced after the movement on the southern (back) thrust. The fractures in this area are subparallel to the backthrust and backlimb. In this location, the backthrust, as seen in seismic data, has a high offset and passes close to the mountain's position. This suggests that the small periclinal zone close to area 6 as predicted by the Gaussian curvature map was formed by the movement on the backthrust. This is supported by the type of fractures that developed in this area. The fractures in area 6 are typically shear fractures with dip-slip movements and trends E-W to ENE-WSW (see Figure 6D).

After restoring the bounding thrusts, the folding of the Jebel Qusaibah structure was restored. The inclined shear unfolding algorithm (Figure 13B) removes the folding deformation by vertical or inclined shear processes, which preserves the bed volume [45]. The pin plane was chosen to be the fold axis surface, which is normal to the unfolding direction and perpendicular to the bedding. The contractional strain produced by the folding was estimated between 0 and -0.23 . This strain was localized in the backlimb and parts of the forelimb. Along with high fracture densities, the backlimb of Jebel Qusaibah is also characterized by having a high number of shear fractures that either trend 
parallelly or perpendicularly to the transport direction. In general, the strains produced by the inclined shear folding of Jebel Qusaibah could highlight the areas that possibly experienced more layer-parallel shear strains during the folding process. Consequently, it can be a useful proxy to predict flexural folding-related fractures.

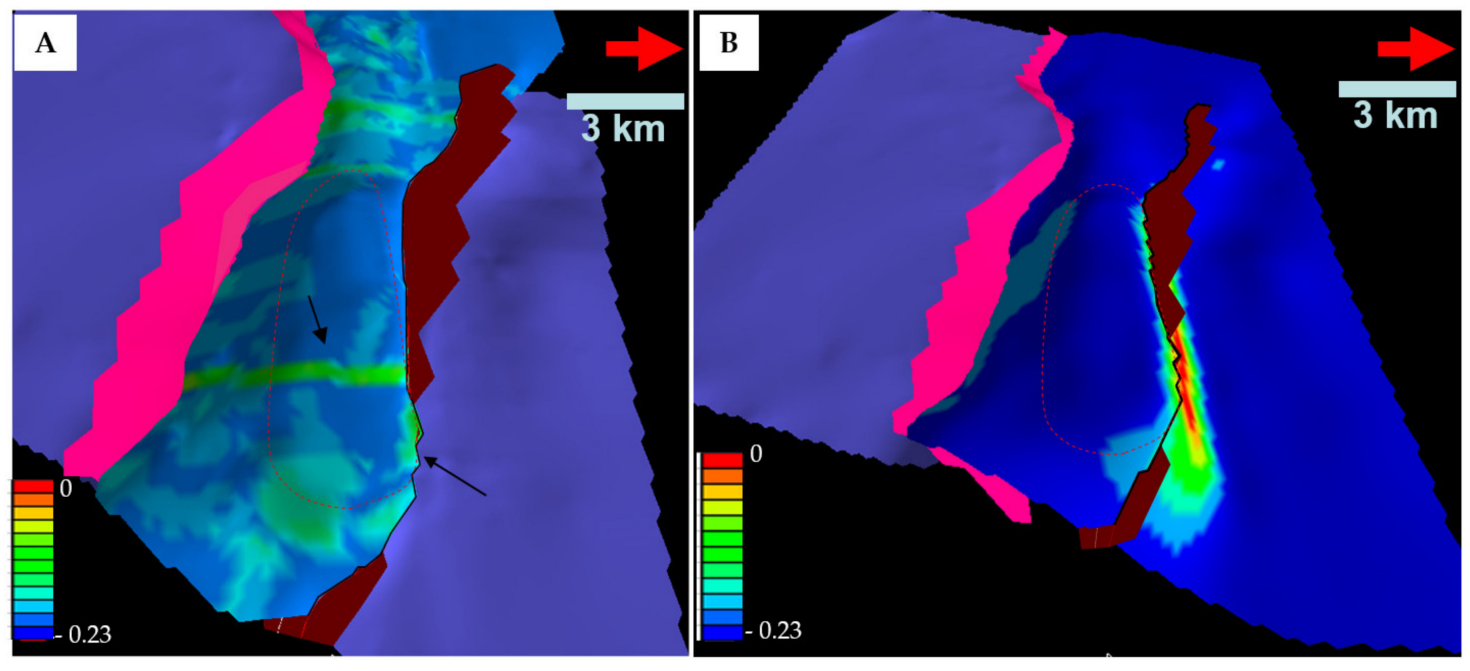

Figure 13. Analysis of the $3 \mathrm{D}$ evolution of Jebel Qusaibah. The red-dashed lines roughly show the positions of Jebel Qusaibah in both maps and the red arrows indicate north. The surfaces of both bounding thrusts are continuous above the top Natih surfaces. (A) Accumulative strains and compressive strains from the movements of faults by fault-parallel flow. The black arrow indicates the northeastern corner of Jebel Qusaibah, which coincides with area 6 in the fracture density contour map. A strip with a high strain value in the middle of the structure indicates a dextral shear stress. This might explain the formation of strike-slip faults in this area of Jebel Qusaibah (see Figures 5 and 9A). (B) Strain produced after unfolding by an inclined shear algorithm. High strain values were found in the backlimb.

\section{Discussion}

\subsection{D Fold Evolution Model vs. the Development of the Small Structures of the Salakh Arch}

\subsubsection{D Kinematic Evolution of Folds}

Figure 14 shows four stages of the kinematic evolution and the development of fractures in the Salakh fold. The model is based on the surface and subsurface geometry of the Salakh-E structure. It is also applicable to other folds with various amounts of shortening. It involves various assumptions, as discussed in the figure caption, about limb rotation and hinge migration based on the correlation with the other Salakh Arch structures or the requirements of area conservations. During the evolution, salt flows in (step B) and out (step D) of the anticlinal core, depending on the excess area in the core. Once the fault becomes nearly isoclinal (e.g., Salakh-E), the growth of amplitude ceases, causing the folding to "lock-up" [46]. This promotes significant thinning of the limbs to accommodate additional shortening. As a result, this process produces bedding-parallel extensional strains, as shown in Figure 14D. 

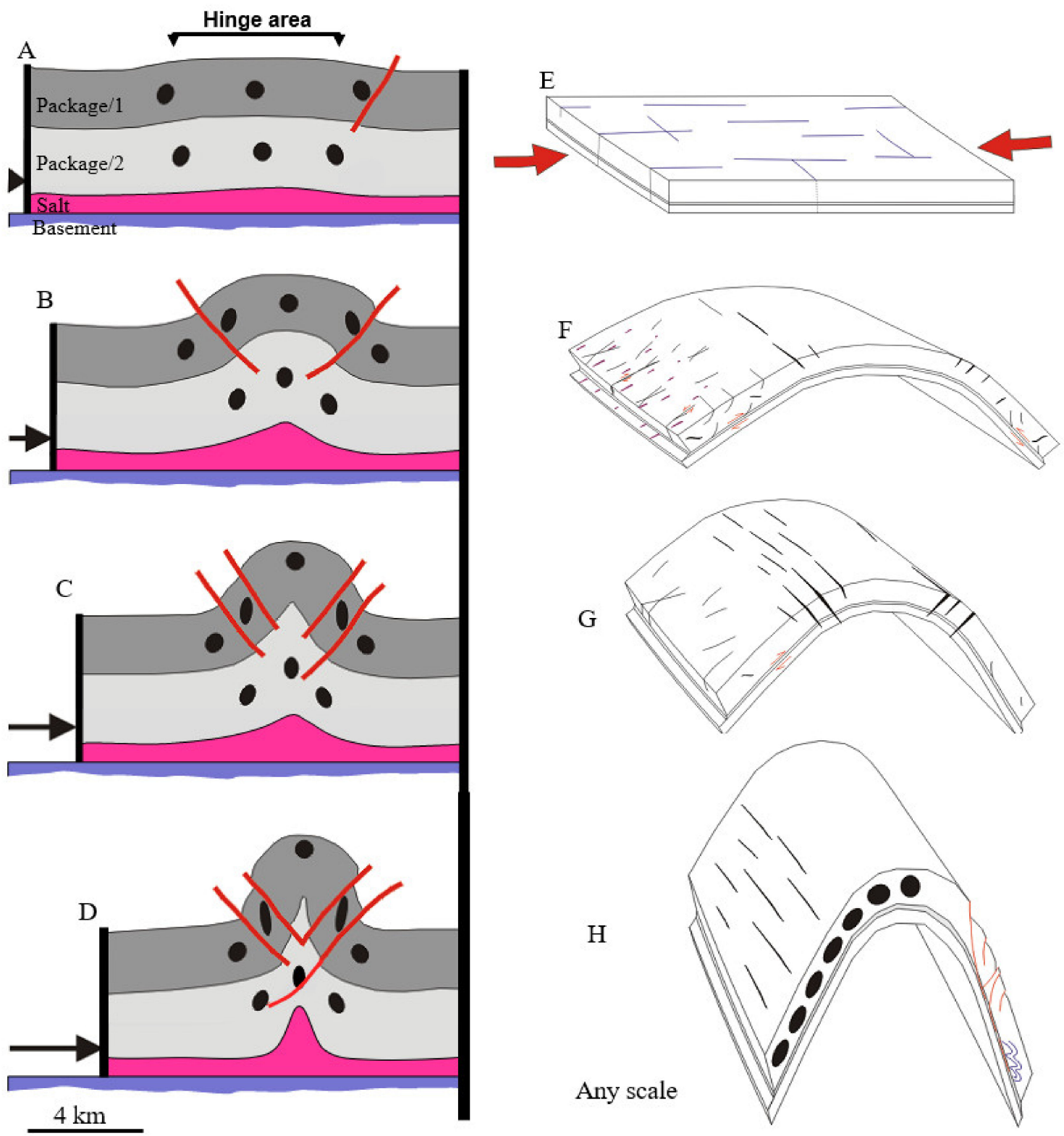

2D Kinematic evolution of Salakh-E based mainly on seismic interpretation and restoration.

Fracture pattern of Salakh-E based on surface observations

Figure 14. The evolutions of large-scale (A-D) and small-scale structures (E-H) can be divided into the following steps: (A,E) initial layer parallel shortening and symmetric buckling with two sets of regional fractures, with the extensional fractures forming perpendicular to the maximum horizontal stress, probably during stress relaxation; $(\mathbf{B}, \mathbf{F})$ formation of bounding thrusts, significant hinge migration (hinge area becomes narrower), and dominant flexural folding (considerable limb rotation); (C,G) continuous rotation of both limbs with minor hinge migration (hinges become more or less fixed) and the outer-arc extension becomes more operative with a reduction in flexural folding; $(\mathbf{D}, \mathbf{H})$ "lock-up" stage with no considerable limb rotation and no hinge migration which causes the flexural folding to cease and the start of homogenous folding, whereby extensional features develop in the flanks as a result of limb thinning. The shortening values are 500, 1500, 2500, and $3500 \mathrm{~m}$ for (A-D), respectively. In general, fold axis-perpendicular fractures most likely form during the early folding stages. In contrast, fold axis-parallel fractures develop during late stages during the tightening of the fold. 
The effect of faulting within package 1 (the carbonate platform sequence) was inferred to be minor $(\approx 20 \%$ of the total shortening). The estimated amount of required strain (internal strain needed to restore the section and that which is expected to occur in the fold core) within package 2 (alternation of sandstone and shale units) ranges from $8.5 \%$ to $12.5 \%$. The strain patterns change during the fold evolution in packages 1 and 2. In package 1, the accumulative layer-parallel shear strains increase during the rotation of the limbs, particularly in stages C and D (Figure 14). High depth-dependent bedding-parallel longitudinal strains occurred in package 2 , particularly during stage 4 , since most of the deformation in this package is accommodated by internal strains.

\subsubsection{Development of Outcrop Small Structures at Salakh Arch}

The minor fault and fracture hierarchies suggest various deformational stages, along with the overall fold geometries in the outcrops of the Salakh Arch. This is summarized in Figure 14E-H, where the stages of which are described as follows:

(E) Layer-parallel shortening-related fractures formed during early stages of the Late Cenozoic compression. These fractures are oriented parallel or perpendicular to the maximum compression axis, which either trends N-S in frontal ramps or is slightly deflected in the oblique and lateral ramp zones, as shown in Figure 11. The perpendicular fractures of $\sigma \mathrm{Hmax}$ probably form during stress relaxation phases. These fracture sets are best identified in the gently dipping or flat hinge areas (Figure 7A) which are the least affected by local strains produced by the folding process.

(F) Flexural folding resulted in layer-parallel detachments that affected all the folds of the Salakh Arch. This mechanism mainly produced conjugate shear fractures, as seen in the rose diagrams of Salakh-E and Salakh-W in Figure 11. These fractures feature a bisector directed to the fold crest as illustrated in Figure 14. Flexural flow occurs when the shear stress is homogenously distributed within the competent units. At the Salakh Arch, this mechanism is mostly represented by the shear fractures that dip away from the fold axis (Figures 7C and 14F). Generally, the fractures related to flexural folding are confined by the given bed or lithology.

(G) The tangential longitudinal strains at Salakh-E feature abundant fold axis-parallel extensional fractures and faults in the hinge zones (maximum curvatures). These fractures are mainly located within thick competent beds or sets of beds, such as the thick beds of Natih-E and Natih-A. This mechanism increases within tighter hinge zones. The outer-arc extension-related fractures were mostly observed in Hinaydil, Salakh-E, Salakh-W, and the northern limb of the Jebel Nahdah fold.

(H) Numerous authors have suggested that flexural folding ceases when fold limbs become steeply dipping during progressive shortening, e.g., $[47,48]$. In this case, folding by flexural slippage or flow will "lock-up" because the fold limb reaches a high angle with respect to oHmax and the bedding-parallel shear stress cannot overcome the normal stresses [12]. This might occur when the limb dip angle approaches $60^{\circ}$. However, the value could vary depending on the initial wavelength/amplitude ratio of the fold and the sufficient supply of incompetent material to fill the fold core [46,49]. When the "lock-up" stage occurs, the parallel folding, in which bed thickness is maintained, is no longer possible and the fold amplifies by homogenous flattening [50]. In this case of homogeneous flattening, the two limbs were thinned, and the hinge area thickened. The culmination walls of Salakh-E and the northern limb of Jebel Nahdah underwent fold axis-perpendicular extension, as manifested by the fold axis-parallel normal faults and extensional fractures in the two limbs. Many of the folds at Salakh-E detached within the weaker units and do not cut the whole stratigraphic sections (e.g., Figure 15). These structures might also be interpreted as gravity collapse structures. However, this latter interpretation is not preferred here because the competent thick beds of Natih-E in the steeply dipping flanks of Salakh-E show evidence of extensive extension distributed along the whole limb, as manifested by limb-parallel fractures (Figures 11 and 14H). 


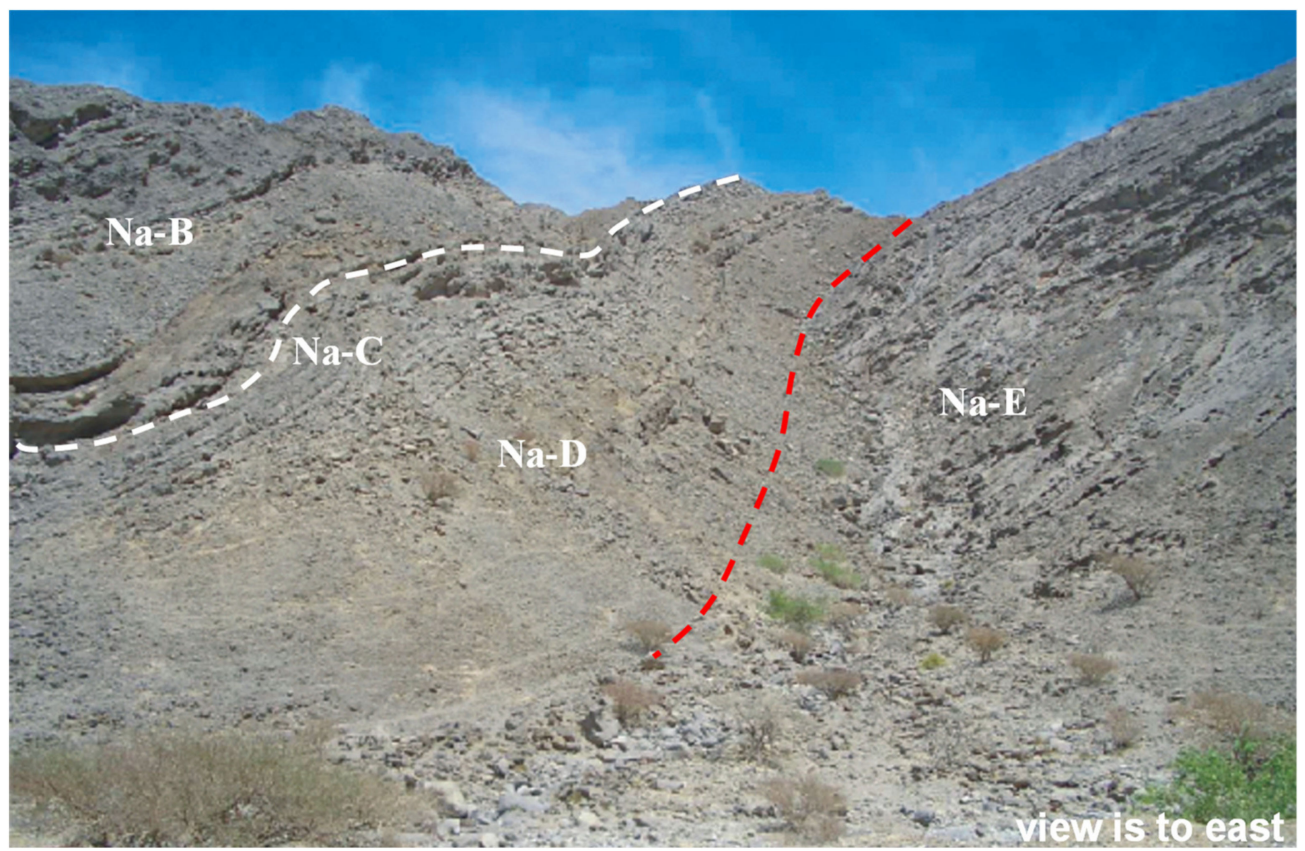

Figure 15. Gentle folds in the northern flank of Salakh-E are highlighted by the dashed white line. These folds detach along the weak units of Natih-D, as highlighted by the dashed red line, i.e., the thick competent beds of Natih-E are not folded.

\subsubsection{Linking 2D Kinematic Evolution Models and Small-Scale Outcrop Structures}

The Salakh Arch folds were possibly initiated as detachment folds with small bounding thrusts [32]. Layer-parallel hinge-directed shear strains produced by limb rotations during the evolution of folds are represented by flexural folding. This folding mechanism is either accommodated by discrete slip surfaces (flexural slip) within interbedded incompetent beds, such as argillaceous limestone, or distributed homogenously within thick beds (flexural flow). Understanding the magnitude of limb rotation during fold development leads to the ability to make good predictions regarding flexural folding-related fractures. At the Salakh Arch, these fractures were mostly seen in the limbs of Salakh-E, Jebel Nahdah, and the northern part of Salakh-W (Figure 11). These limbs have undergone a significant amount of steepening, as indicated by the magnitudes of their dips. These fractures were hardly observed in the limbs of Jebel Madmar with a general limb dip angle of less than $30^{\circ}$.

The effects of tangential longitudinal strains can be mainly seen in significantly curved hinges [44]. The accumulative and incremental strains in migrating hinges are always shortening. However, the incremental longitudinal strains in fixed hinges are extensional in the upper part of the fold [51]. Therefore, outer-arc extension fractures mostly develop with fixed hinges. The hinges of the Salakh Arch folds plausibly became fixed in the late stages of shortening during the process of fold tightening. These fractures are not likely to develop until significant shortening and fold tightening take place. Moreover, the fractures that formed because of outer-arc extension were not seen in tight hinges that developed near the bounding thrusts. An example of this is the tight hinges in the southern limb of Jebel Madmar which are located close to major thrusts (Figure 10), where the accumulative strains within these hinges have always been compressional.

Extensional structures parallel to the bedding strike were also formed in the limbs of the Salakh-E and Jebel Nahdah folds. These indicate bedding-parallel longitudinal strains in the limb regions. No similar structures have been seen in the other folds of the Salakh Arch. The kinematic model of Salakh-E predicts possible limb thinning caused by the inability of folds to sustain growth by limb rotation. Consequently, when the fold reached the "lock-up" stage, new sets of fold-parallel extensional fractures developed in the limbs. 


\subsection{Testing Fracture Models Based on General Understanding of Fold Fracture Relationships at the Salakh Arch}

Figure 16A summarizes the pattern of regional fractures. These fractures usually show a regular spacing which is roughly consistent along various fold parts. Price and Cosgrove [18], Fischer and Wilkerson [16], and Florez-Nino et al. [10] proposed that regional fractures usually trend perpendicularly and less commonly parallel to the fold axis. These assumptions are supported here by the field data from the Salakh Arch, as shown in Figure 7A. The regional fractures are best seen in the flat crests, because these areas are not highly affected by fold-related strains. Their spacings vary between about $1.5 \mathrm{~m}$ to several meters apart. They are mostly extensional (mode I) and have small apertures or openings. Figure 16 also shows the development of fault-related fractures close to the bounding fault. These fractures are commonly shear fractures with a type of movement similar to the main fault type, as discussed in previous works, e.g., $[1,8,52]$. They usually intensively form subparallel to the major fault plane and in their proximity. The densities of these fractures increase as the fault displacement increases. As observed from the field data, fault-related fractures are usually more intensive in the side of the hanging wall of the main fault. They are similar to the "set 3 " fractures that were predicted by [53].
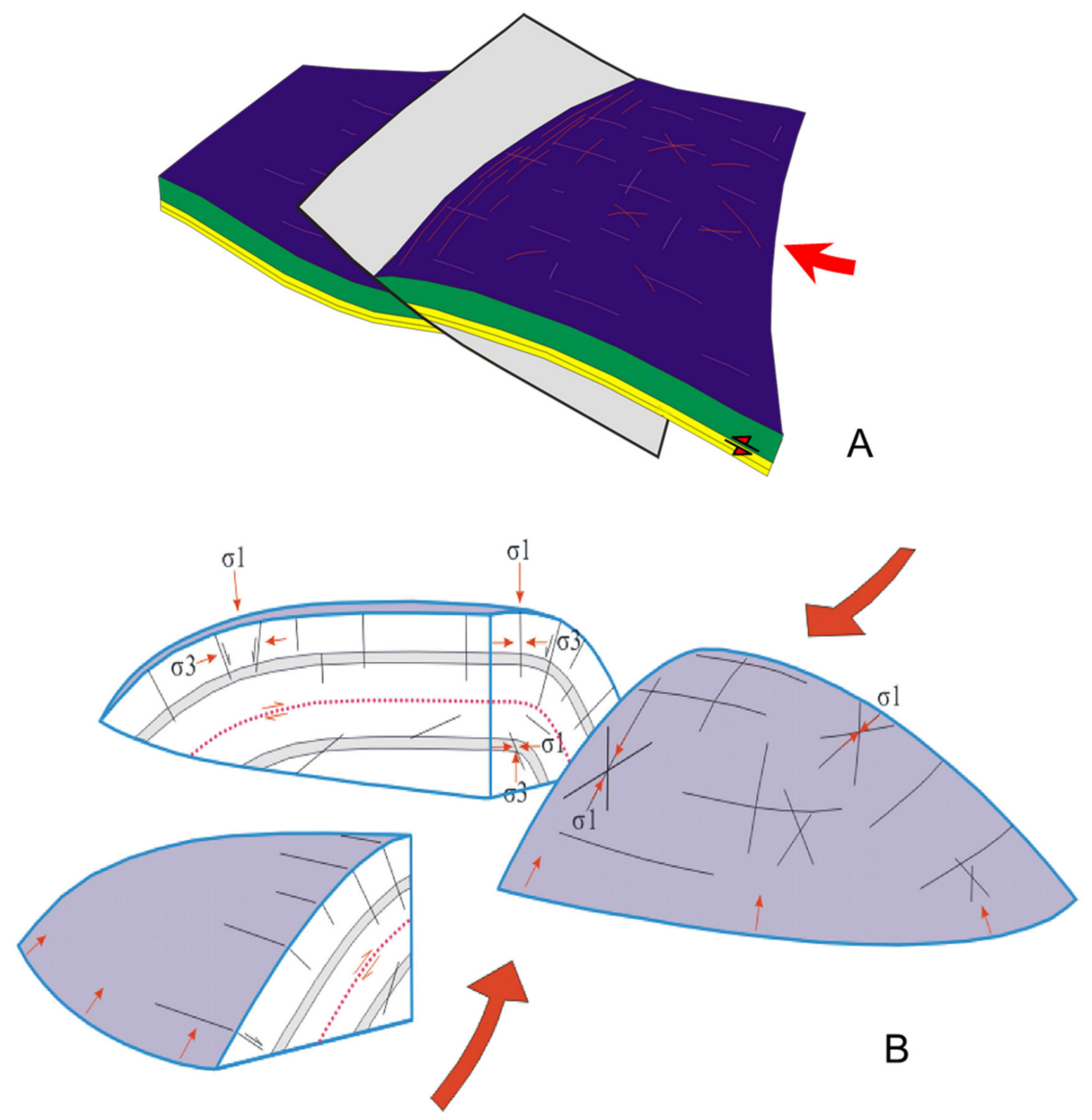

Figure 16. (A) A simple summary of the regional and fault-related fractures produced during early stages of shortening. (B) Rationale of fractures related to local strains produced by folding process. The rationale is mainly constructed and modified from the works of Stearns [17], Price and Cosgrove [18], and Ramsay [44]. 
As shown by Figure 16B, tangential longitudinal and flexural flow strains are more prominent in thick competent units. In contrast, flexural slippage is an important mechanism in well-stratified thin units $[18,43]$. Conjugate shear fractures are more common in the middle parts of fold limbs. These are mainly produced because of flexural folding. As observed in the field, bedding planes serve as slip surfaces to accommodate the flexural slip folding. These planes often have striations and steps that indicate the sense of movement. Fold axis-parallel fractures mainly form because of outer-arc extension, which also forms rarer fold axis-perpendicular fractures in the two plunges. Gently dipping shear fractures with a reverse type of movement can form in the inner-arc compression zone which is separated by the neutral surface from the outer-arc extension zone, as predicted by Stearns [17].

The distributions of minor faults and fractures vary significantly with their structural position in large structures. Adjacent areas within individual folds might considerably differ in their orientations and densities of fracture sets because they have different structural evolution histories (e.g., area 6 in Figure 6). This contradicts the previous model and assumptions of Jamison [9], who stated, using the Monkshood anticline as an example, that the densities and apertures of fractures within folds are not correlated with their structural positions. The results presented here also oppose some findings of Hanks et al. [12], who suggested that the analysis of fold curvatures, considering the Lisburne Group folds, is not a reliable method for predicting the density of fold-related fractures. Although the fracture apertures do not seem to increase in areas of high curvatures here, thus disagreeing with Murray [4], the fracture density could be predicted well by the curvature analyses, thus supporting the models by Lisle [13,15].

\section{Conclusions}

Three approaches have been used here to compare between the kinematics and geometries of the large structures and fracture patterns of the Salakh Arch. Understanding how the arc there developed through time can have great implications for the prediction of faults and fractures. Regions of the arc that experienced angular shear strains were related to differential shortening that corresponds to areas which have a high density of arc-perpendicular extensional faults and fractures.

The densities of the fractures of the Salakh Arch can be as predicted well via various static geometrical attributes. Low values for the finite dip and Gaussian curvature might indicate minimal local strain and subsequently low fracture densities. The Gaussian curvature analysis can identify zones of irregular strains and thus high fracture density. The analysis of this geometrical attribute for Jebel Qusaibah, as shown by the data for its northeastern corner, is a useful tool to detect minor periclines within large structures. It can also reveal areas of irregular shapes close to major fault planes. The simple curvature map can be used as a proxy for the local strains produced by folding. Thus, it can detect fold-related fractures. The map displays high values here for the northern hinge zone and the backlimb of Jebel Qusaibah, like the results obtained for the unfolding restoration. The accumulative strains that resulted from the movements of the front and back thrusts may represent areas of abundant fault-related fractures that developed in the vicinity of the major bounding faults because of the movements along these faults. The strains produced by the forward fold modeling of the Jebel Qusaibah fold were found to be reliable in terms of predicting layer-parallel shear strains. Thus, it can be used as a proxy for flexural folding.

Two-dimensional kinematic models of fold evolution can also be used to understand the strain patterns during different stages of fold development. Hinge migration is a prominent mechanism during the early stages of deformation. The hinges become fixed during the later stages, thus promoting the development of tangential longitudinal strains in the hinge zones. Outer-arc extension-related fractures have been seen in the Salakh Arch folds that have significantly curved hinges, particularly hinges that have developed away from major thrust zones. Limb rotation mainly takes place during progressive shortening. This mechanism produces layer-parallel shear strains in the limb zones, which is usually accommodated by flexural folding and results in shear fractures that are oblique to the fold axis. The steep limbs of Salakh-E suggest that flexural folding ceased during the final stages of fold 
development. The cessation of limb rotation and flexural folding promoted significant thinning of the fold limbs as the fold continued to grow by homogeneous flattening. The thinning of fold limbs might be responsible for the fold axis-parallel fractures that formed in the limbs of Salakh-E.

Jebel Madmar represents an open fold structure with a geometry that is largely controlled by the bounding thrusts. The fracture orientations (NE-SW and NW-SE) do not change significantly in different parts of the fold. Most of these fractures were most likely formed before Cenozoic folding. The effects of the local strains produced by the folding process are thought to be minor at Jebel Madmar. In general, the structures that mainly underwent fold-accommodated shortening, such as Salakh-E, were the most affected by fold-related fractures. In contrast, the fractures in fault-controlled segments like Jebel Madmar were usually pre-existing, fault-related, or formed by the kinematics of arc evolution.

The distributions of fractures in a folded unit vary significantly with their structural position. Good predictions of fractures must involve understanding of the layer-parallel longitudinal and shear strains, along with the layer normal shear strains during various stages of folding. The protocols developed during this study and their results may have general applicability to the investigations of fracture patterns in other folds.

Funding: The project was partly funded by Petroleum Development Oman, the leading exploration and production company in the Sultanate of Oman.

Acknowledgments: The author thanks Rob Butler and Martin Casey for all their useful discussion while conducting this work. Midland Valley is appreciated for providing their software packages (2DMove and 3DMove) during this project.

Conflicts of Interest: The author declares no conflict of interest. The funders had no role in the design of the study; in the collection, analyses, or interpretation of data; in the writing of the manuscript, or in the decision to publish the results.

\section{References}

1. Hennings, P.; Olson, J.E.; Thompson, L.B. Combining Outcrop Data and Three-Dimensional Structural Models to Characterize Fractured Reservoirs: An Example from Wyoming. AAPG Bull. 2000, 84, 830-849. [CrossRef]

2. Cosgrove, W.J.; Ameen, M.S. A comparison of the geometry, spatial organisation and fracture patterns associated with forced folds and buckle folds. In Forced Folds and Fractures; Cosgrove, J.W., Ameen, M.S., Eds.; Special Publication of the Geological Society of London: London, UK, 2000.

3. Casey, M.; Butler, R.W.H. Modelling approaches to understanding fold development: Implications for hydrocarbon reservoirs. Mar. Pet. Geol. 2004, 21, 933-946. [CrossRef]

4. Murray, J.G.H. Quantitative Fracture Study-Sanish Pool, Mckenzie County, North Dakota. AAPG Bull. 1968, 52, 57-65. [CrossRef]

5. Ameen, M.S. Fractography and fracture characterization in the Permo-Triassic sandstones and the Lower Palaeozoic Basement, West Cumbria, UK. Geol. Soc. Lond. 1995, 92, 97-147. [CrossRef]

6. Cooke, M.; Mollema, P.N.; Pollard, D.D.; Aydin, A. Interlayer slip and joint localization in the East Kaibab Monocline, Utah: Field evidence and results from numerical modelling. Geol. Soc. Lond. 1999, 169, $23-49$. [CrossRef]

7. Bergbauer, S.; Pollard, D.D. A new conceptual fold-fracture model including prefolding joints, based on the Emigrant Gap anticline, Wyoming. GSA Bull. 2004, 116, 294. [CrossRef]

8. Li, Y.; Hou, G.; Hari, K.; Neng, Y.; Lei, G.; Tang, Y.; Zhou, L.; Sun, S.; Zheng, C. The model of fracture development in the faulted folds: The role of folding and faulting. Mar. Pet. Geol. 2018, 89, 243-251. [CrossRef]

9. Jamison, W.R. Geometric analysis of fold development in overthrust terranes. J. Struct. Geol. 1987, 9, $207-219$. [CrossRef]

10. Florez-Niño, J.-M.; Aydin, A.; Mavko, G.; Antonellini, M.; Ayaviri, A. Fault and fracture systems in a fold and thrust belt: An example from Bolivia. AAPG Bull. 2005, 89, 471-493. [CrossRef]

11. Hanks, J.L.C.L.; Krumhardt, A.P. Lithologic and Structural Controls on Natural Fracture Distribution and Behavior Within the Lisburne Group, Northeastern Brooks Range and North Slope Subsurface, Alaska. AAPG Bull. 1997, 81, 1700-1720. [CrossRef] 
12. Hanks, C. Character, relative age and implications of fractures and other mesoscopic structures associated with detachment folds: An example from the Lisburne Group of the northeastern Brooks Range, Alaska. Bull. Can. Pet. Geol. 2004, 52, 121-138. [CrossRef]

13. Lisle, R.J. Detection of Zones of Abnormal Strains in Structures Using Gaussian Curvature Analysis. AAPG Bull. 1994, 78, 1811-1819. [CrossRef]

14. Lisle, R.J. Predicting patterns of strain from three-dimensional fold geometries: Neutral surface folds and forced folds. Geol. Soc. Lond. 1999, 169, 213-221. [CrossRef]

15. Lisle, R.J. Constant bed-length folding: Three-dimensional geometrical implications. J. Struct. Geol. 1992, 14, 245-252. [CrossRef]

16. Fischer, M.P.; Wilkerson, M.S. Predicting the orientation of joints from fold shape: Results of pseudo-three-dimensional modeling and curvature analysis. Geology 2000, 28, 15-18. [CrossRef]

17. Stearns, D. Faulting and forced folding in the Rocky Mountains foreland. In Laramide Folding Associated with Basement Block Faulting in the Western United States; Matthews, V., III, Ed.; Geological Society of America: Boulder, CO, USA, 1978; pp. 1-37.

18. Price, N.J.; Cosgrove, J.W. Analysis of Geological Structures; Cambridge University Press: Cambridge, UK, 1990.

19. Dercourt, J.; Zonenshain, L.; Ricou, L.-E.; Kazmin, V.; Le Pichon, X.; Knipper, A.; Grandjacquet, C.; Sbortshikov, I.; Geyssant, J.; Lepvrier, C.; et al. Geological evolution of the tethys belt from the atlantic to the pamirs since the LIAS. Tectonophysics 1986, 123, 241-315. [CrossRef]

20. Searle, M. The Geology of the Oman Mountains-An Outline of Their Origin. J. Struct. Geol. 1996, 18, 861-862. [CrossRef]

21. Hanna, S.S. The Alpine deformation of the Central Oman Mountains. Geol. Soc. Lond. 1990, 49, 341-359. [CrossRef]

22. Glennie, K.W.; Boeuf, M.G.A.; Hughes-Clark, M.W.; Moody-Stuart, M.; Pillar, W.F.H.; Reinhardt, B.M. Geology of the Oman Mountains. Trans. R. Dutch Geol. Min. Soc. 1974, 31, 423. [CrossRef]

23. Skelton, P.W.; Nolan, S.C.; Scott, R.W. The Maastrichtian transgression onto the northwestern flank of the Proto-Oman Mountains: Sequences of rudist-bearing beach to open shelf facies. Geol. Soc. Lond. 1990, 49, 521-547. [CrossRef]

24. Warburton, J.; Burnhill, T.J.; Graham, R.H.; Isaac, K.P. The evolution of the Oman Mountains Foreland Basin. Geol. Soc. Lond. 1990, 49, 419-427. [CrossRef]

25. Loosveld, R.J.; Bell, A.; Terken, J.J. The tectonic evolution of interior Oman. GeoArabia 1996, 1, $28-51$.

26. Al-Kindi, M.H.; Richard, P.D. The main structural styles of the hydrocarbon reservoirs in Oman. Geol. Soc. Lond. 2014, 392, 409-445. [CrossRef]

27. Filbrandt, J.B.; Al-Dhahab, S.; Al-Habsy, A.; Harris, K.; Keating, J.; Al-Mahruqi, S.; Robertson, T. Kinematic interpretation and structural evolution of North Oman, Block 6, since the Late Cretaceous and implications for timing of hydrocarbon migration into Cretaceous reservoirs. GeoArabia 2006, 11, 97-140.

28. Boote, D.R.D.; Mou, D.; Waite, R.I. Structural evolution of the Suneinah Foreland, Central Oman Mountains. Geol. Soc. Lond. 1990, 49, 397-418. [CrossRef]

29. Mount, V.S.; Crawford, R.I.; Bergman, S.C. Regional structural style of the central and southern Oman Mountains: Jebel Akhdar, Saih Hatat, and the northern Ghaba Basin. GeoArabia 1998, 3, 475-490.

30. Searle, M.P.; James, N.P.; Calon, T.J.; Smewing, J.D. Sedimentological and structural evolution of the Arabian continental margin in the Musandam Mountains and Dibba zone, United Arab Emirates. GSA Bull. 1983, 94, 1381. [CrossRef]

31. Hansman, R.J.; Ring, U.; Thomson, S.N.; Brok, B.D.; Stübner, K. Late Eocene Uplift of the Al Hajar Mountains, Oman, Supported by Stratigraphy and Low-Temperature Thermochronology. Tectonics 2017, 36, 3081-3109. [CrossRef]

32. Al-Kindi, M. Timing, Mechanics and Controls of the Evolution of the Southernmost Part of the Oman Mountains: The Salakh Arch. Geoscience 2020, 10, 95. [CrossRef]

33. Aldega, L.; Carminati, E.; Scharf, A.; Mattern, F.; Al-Wardi, M. Estimating original thickness and extent of the Semail Ophiolite in the eastern Oman Mountains by paleothermal indicators. Mar. Pet. Geol. 2017, 84, 18-33. [CrossRef]

34. Moraetis, D.; Scharf, A.; Mattern, F.; Pavlopoulos, K.; Forman, S.L. Quaternary Thrusting in the Central Oman Mountains-Novel Observations and Causes: Insights from Optical Stimulate Luminescence Dating and Kinematic Fault Analyses. Geoscience 2020, 10, 166. [CrossRef] 
35. Van Buchem, F.S.P.; Razin, P.; Homewood, P.W.; Oterdoom, W.H.; Philip, J. Stratigraphic organization of carbonate ramps and organic-rich intrashelf basins: Natih Formation (middle Cretaceous) of northern Oman. AAPG Bull. 2002, 86, 21-53. [CrossRef]

36. Béchennec, F.; Wyns, R.; Roger, J.; Le Metour, J.; Chevrel, S. Geological Map of Nazwa NF40-07: Scale 1/250,000, Explanatory Notes; Directorate General of Minerals, Ministry of Petroleum and Minerals: Muscate, Oman, 1992.

37. Storti, F.; Balsamo, F.; Clemenzi, L.; Mozafari, M.; Solum, J.; Swennen, R.; Taberner, C.; Tueckmantel, C.; Al-Kindy, M. Complex fault-fold interactions during the growth of the Jabal Qusaybah anticline at the western tip of the Salakh Arch, Oman. Tectonics 2015, 34, 488-509. [CrossRef]

38. Corradetti, A.; Spina, V.; Tavani, S.; Ringenbach, J.; Sabbatino, M.; Razin, P.; Laurent, O.; Brichau, S.; Mazzoli, S. Late-stage tectonic evolution of the Al-Hajar Mountains, Oman: New constraints from Palaeogene sedimentary units and low-temperature thermochronometry. Geol. Mag. 2020, 157, 1031-1044. [CrossRef]

39. Balsamo, F.; Clemenzi, L.; Storti, F.; Mozafari, M.; Solum, J.; Swennen, R.; Taberner, C.; Tueckmantel, C. Anatomy and paleofluid evolution of laterally restricted extensional fault zones in the Jabal Qusaybah anticline, Salakh arch, Oman. GSA Bull. 2016, 128, 957-972. [CrossRef]

40. Al-Wardi, M.; Butler, R.W.H. Constrictional extensional tectonics in the northern Oman mountains, its role in culmination development and the exhumation of the subducted Arabian continental margin. Geol. Soc. Lond. 2007, 272, 187-202. [CrossRef]

41. Twiss, R.J.; Moores, E.M. Structural Geology; Freeman: New York, NY, USA, 1992.

42. Ozkaya, S.I.; Richard, P.D. Fractured Reservoir Characterization Using Dynamic Data in a Carbonate Field, Oman. SPE Reserv. Eval. Eng. 2006, 9, 227-238. [CrossRef]

43. Donath, A.F.; Parker, R.B. Folds and folding. Geol. Soc. Am. Bull. 1964, 75, 45-62. [CrossRef]

44. Ramsay, J.G. Folding and Fracturing of Rocks; Mc Graw Hill Book Company: New York, NY, USA, $1967 ;$ p. 568.

45. Midland-Valley. 2DMoveV4.1 and 3DMoveV4.1; Tutorial Books; Midland-Valley: Aiken County, SC, USA, 2004.

46. Poblet, K.M.J. Geometry and Kinematics of Single-Layer Detachment Folds. AAPG Bull. 1996, 80, 1085-1109. [CrossRef]

47. Tanner, P.G. The flexural-slip mechanism. J. Struct. Geol. 1989, 11, 635-655. [CrossRef]

48. Woodward, N.B. Low-amplitude evolution of break-thrust folding. J. Struct. Geol. 1997, 19, 293-301. [CrossRef]

49. Gutierrez-Alonso, G.; Gross, M.R. Structures and mechanisms associated with development of a fold in the Cantabrian Zone thrust belt, NW Spain. J. Struct. Geol. 1999, 21, 653-670. [CrossRef]

50. Hobbs, B. The analysis of strain in folded layers. Tectonophysics 1971, 11, 329-375. [CrossRef]

51. Epard, J.L.; Groshong, R.H., Jr. Kinematic model of detachment folding including limb rotation, fixed hinges and layer-parallel strain. Tectonophysics 1995, 247, 85-103. [CrossRef]

52. Mobasher, K.; Babaie, H.A. Kinematic significance of fold- and fault-related fracture systems in the Zagros mountains, southern Iran. Tectonophysics 2008, 451, 156-169. [CrossRef]

53. Cooper, M. The analysis of fracture systems in subsurface thrust structures from the Foothills of the Canadian Rockies. In Thrust Tectonics; Chapman and Hall: London, UK, 1992; pp. 391-405.

Publisher's Note: MDPI stays neutral with regard to jurisdictional claims in published maps and institutional affiliations.

(C) 2020 by the author. Licensee MDPI, Basel, Switzerland. This article is an open access article distributed under the terms and conditions of the Creative Commons Attribution (CC BY) license (http://creativecommons.org/licenses/by/4.0/). 